\title{
Life skills: Psychosocial and interpersonal skills for adolescent girls in urban Ghana-Mentor's guide
}

Population Council

Follow this and additional works at: https://knowledgecommons.popcouncil.org/departments_sbsr-pgy

Part of the Demography, Population, and Ecology Commons, Family, Life Course, and Society Commons, International Public Health Commons, Maternal and Child Health Commons, Medicine and Health Commons, and the Women's Health Commons How does access to this work benefit you? Let us know!

\section{Recommended Citation}

"Life skills: Psychosocial and interpersonal skills for adolescent girls in urban Ghana-Mentor's guide." Accra: Population Council, 2010. 


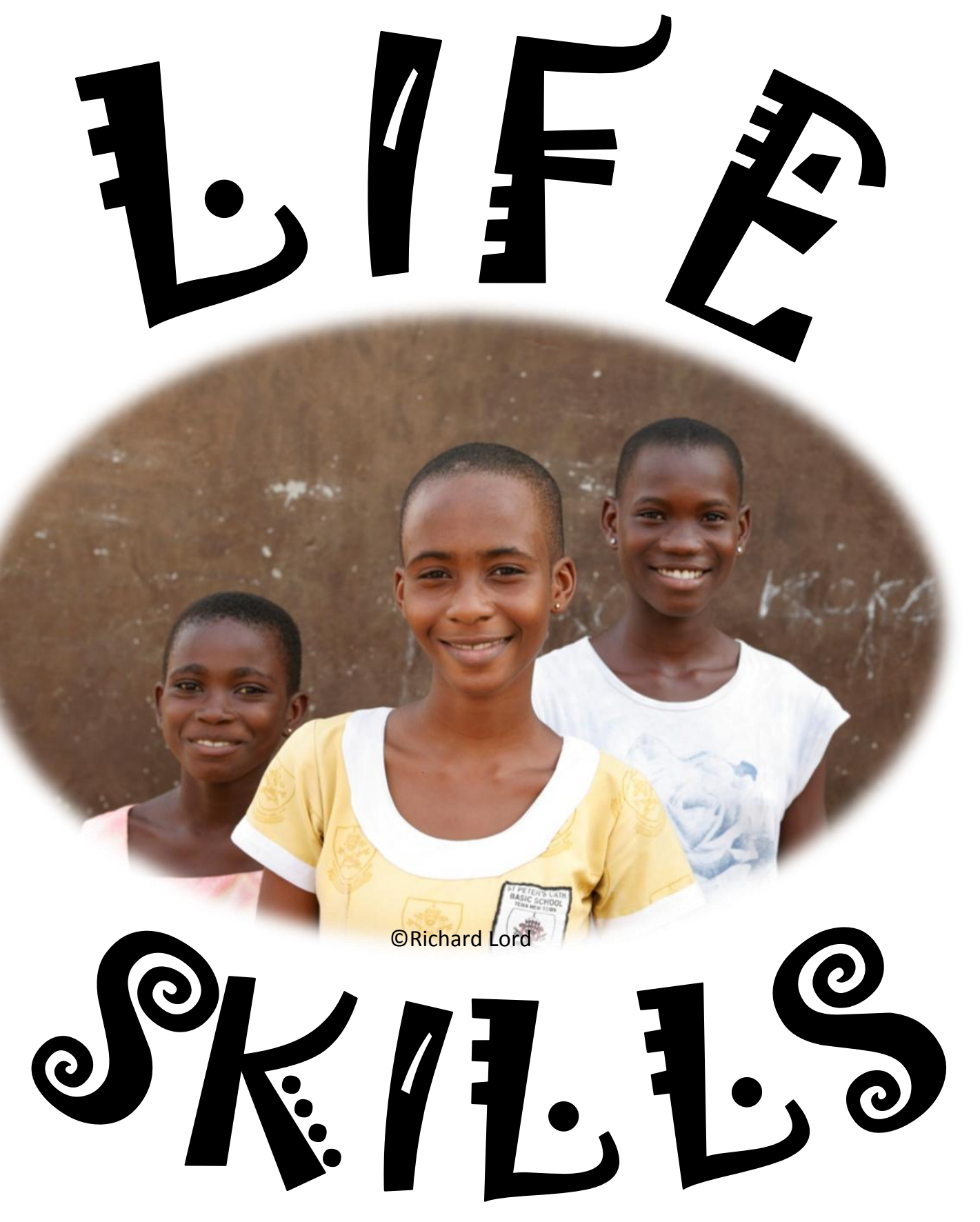

Psychosocial and Interpersonal Skills for Adolescent Girls in Urban Ghana

MENTOR's GUIDE 



\section{Acknowledgements}

This curriculum was developed by Bridgit Burns, MPH student at Columbia University's Mailman School of Public Health, with guidance from Sarah Engebretsen at the Population Council. The material contained is largely adapted from a variety of existing curricula, including CEDPA's Choose A Future: Issues and Options for Adolescent Boys in India, Population Council's Tuko Pamoja: Adolescent Reproductive Health and Life Skills Curriculum, PATH African Youth Alliance's Life Planning Skills: A Curriculum for Young People in Africa, Ghana version, and AED Center for Gender Equality's Girls' Success: Mentoring Guide for Life Skills. We would like to thank Right to Play RIGHT for training our mentors during the pilot phase of this program, and for allowing continued use of a selection of the valuable lessons from their "Live Safe Play Safe" and "Red Ball Child Play" manuals. Thank you to the staff at the Population Council Ghana office, including Michael Tetteh, Sabina Wilson, Susie Arku, Abigail Addo-Quaye, and Selina Esantsi, for their guidance and input throughout the development of this curriculum. Thank you to Richard Lord for his photographs, several of which appear throughout this manual. Finally, special thanks to the adolescent girls of U-compound for their energy throughout the pilot phase and their enthusiasm for learning about life skills and other important skills for adulthood.

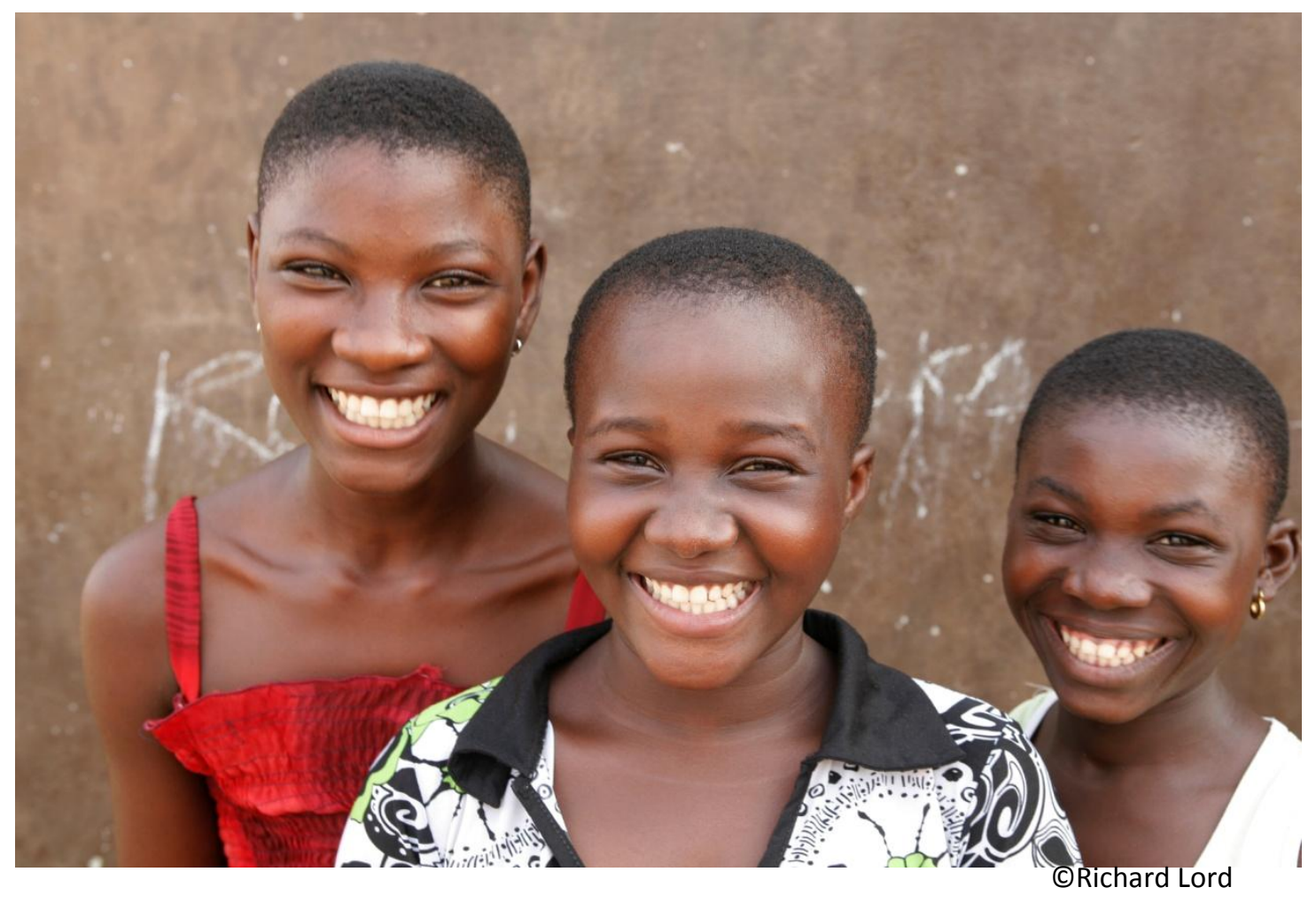

Mehdasi! 


\section{(1) Population Council}

The Population Council is an international, nonprofit, nongovernmental organization that seeks to improve the well-being and reproductive health of current and future generations around the world and to help achieve a humane, equitable, and sustainable balance between people and resources. The Council conducts research in three areas: HIV and AIDS; poverty, gender, and youth; and reproductive health. Established in 1952, the Council is governed by an international board of trustees. Its New York headquarters supports a global network of regional and country offices.

Copyright (C) 2010 by the Population Council

This document may be reproduced in whole or part without permission of the Population Council provided full source citation is given and reproduction is not for commercial purposes.

\section{Suggested citation:}

Population Council, "Life Skills: Psychosocial and Interpersonal Skills for Adolescent Girls in Urban Ghana," New York: The Population Council, November 2010.

For more information, please contact:

Bridgit Burns

bridgit.burns@gmail.com
Sarah Engebretsen

sengebretsen@popcouncil.org
Selina Esantsi

sesantsi@popcouncil.org 


\section{Introduction}

This curriculum is not intended as a stand-alone intervention, but rather is one component of the Population Council's "Safe Spaces" asset-building program for vulnerable adolescent girls in urban Ghana. School dropout is common among urban adolescent girls in Ghana, leading to increased social isolation and high rates of teenage pregnancy. The program approach is based on giving girls a safe, girlonly space where they can meet friends and learn about important topics under the guidance of a female mentor. Urban adolescent girls face a wide range of risk factors, and often show incredible talent, energy, and resiliency. A comprehensive range of programming will provide the best opportunities for them to grow into strong, confident, and wise young women.

This Life Skills module is meant to be taught in conjunction with General Health, Sexual and Reproductive Health, and Financial Literacy. The curriculum consists of twenty sessions, ranging from 60-105 minutes. Most sessions should take about 90 minutes to complete. The sessions are designed to be completed in the order listed, with each session being conducted in full on separate days. The number of sessions completed per week or per month is flexible and can be adapted to the needs of the participants.

The activities in this guide are intended for use with adolescent girls ages 10-13, but many are also appropriate for use with older girls. This curriculum takes an interactive approach, using various games, role-plays, small group activities, and discussions to enhance the participants' learning and skill-building. Many of the activities assume that the participants can read and write at least at a basic level, and they may require modifications for use with low literacy groups. 


\section{What Is a Mentor?}

In this program, mentors are women role models from the community who lead the weekly sessions with girls. A 'role model' is someone whom girls can admire and look up to because she leads a good life. Mentors were once girls themselves-very much like the girls whom they now mentor - and have made good decisions that have led to success in life. Girls learn from hearing about mentors' experiences.

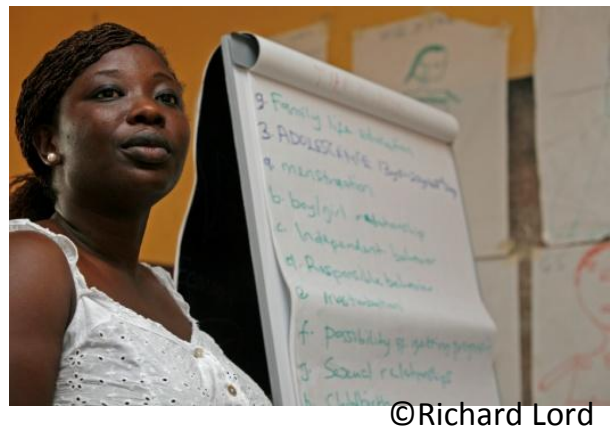

A mentor helps girls develop the skills to make good choices. This includes helping girls to see different options or different ways of solving challenges and then making the best decisions possible. Mentors raise questions and help girls think about important issues, about making good decisions, and about succeeding in life. A mentor encourages girls to stay in school and have aspirations for themselves beyond school. A mentor has a real concern for the young women in the community. She builds trust. She speaks wisely and listens closely. She plans mentoring sessions and activities. A mentor is willing to do what she can to help girls succeed.

Mentoring gives girls the chance to spend time with a trusted adult who accepts them for who they are. A mentor inspires girls to do their best and helps them to succeed.

It is not difficult to be a good mentor if one follows a few important guidelines:

* Listen! A good mentor is a good listener. She listens and helps girls feel comfortable enough to talk openly. A good listener does not interrupt or judge what girls are saying. She values girls' feelings and ideas, and this helps to build trust. A mentor asks questions to encourage girls to speak out. Careful questioning helps mentors learn what girls are thinking.

* Share! A good mentor also shares stories about her experiences. These stories should not only be about successes but also about hardship and challenges. By being open and honest with girls, mentors gain girls' trust and respect. Girls learn more from mentors when they understand that even role models have highs and lows like everyone else.

* Do not judge or pick favorites! By not judging girls, a mentor helps girls feel safe to share new ideas without fear of mistakes. A mentor does not show favor to any one girl over another but shows all girls that they are valued and important.

* Build Trust! It is very important that mentors do not share private information from girls with others. Keeping private information to oneself helps build trust between a mentor and the girls. However, sometimes a mentor might feel that a girl is in danger or might be abused. This is the time when the mentor can share private information with another trusted adult to remove the girl from danger. 
* Do not expect gifts! Mentors should never ask for money or gifts from girls, girls' families, or anyone else in the community. This sends a very bad message.

* Be dependable! A mentor is faithful in carrying out her mentoring duties. Girls should be able to rely on mentors to keep their word. This includes commitments to regular meetings, arriving at meetings on time, and following through on what mentors promise to do.

* Give wise counsel! A good mentor gives clear guidance to girls. She does not make choices for girls or tell them what to do. By her advice, a mentor can help girls make better choices for themselves. A mentor does not have to know all the answers. She has the wisdom, though, to know when to seek more information from others.

* Have fun! A good mentor enjoys mentoring and spending time with girls. The girls will know by her speech and actions that their mentor is happy to spend time with them.

\section{How to Use This Guide}

Each session description begins with a box that lists the following information:

* Session Objectives - learning goals for the session

* Materials Needed - what you need to complete the activities in the session

* Session Outline - a list of the activities included in the session, including the approximate time for each one

* Total Time - an estimate of the length of time needed to complete all the activities in the session

Use the times listed for each activity as a guideline. Depending on your participants, each activity may take more or less time, so don't be surprised.

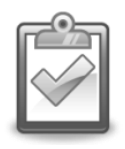

Some activities require the mentor to do some preparation before the session. Look out for this checklist icon, which will indicate you need to do some work ahead of time. It's always a good idea to read over each session in advance to make sure you are prepared.

Many of the session descriptions have a section of BACKGROUND NOTES, which include information for the mentor to read beforehand, to make sure you have a good understanding of the topic. You can also refer to the information in this section to help you answer any questions that the girls may have.

Each activity has step-by-step INSTRUCTIONS to help guide you in facilitating the session. Some of the activities use handouts or other materials that you will find at the end of each session description. These handouts and the page number will be listed in the box at the beginning of the session description under Materials Needed. Each handout has the name of the activity it is for written on the upper-right corner. Several of the activities require each girl to have a program journal, a notebook that they can use throughout the entire course to record their thoughts and various exercises. 


\section{Every session ends with a TAKING IT HOME activity, that will be shown in a box like this.}

These activities are an opportunity for the girls to take the lessons they have learned and apply them to their daily lives. They often involve talking with friends or family members. Every session (except the first one) starts with a recap of the TAKING IT HOME activity from the previous session.

\section{Some of the sessions have a PLANNING}

AHEAD banner at the end. These indicate that the mentor needs to alert the girls about something they need to do or think about in preparation for a future session. The banners will tell you specifically what preparations are needed and what session they are for.

\section{Good Luck and Have Fun!}




\section{Contents}

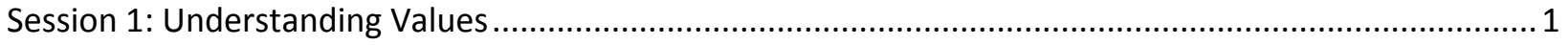

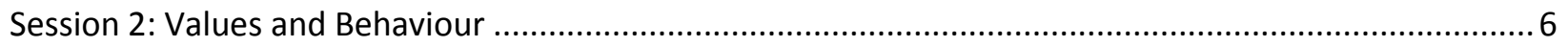

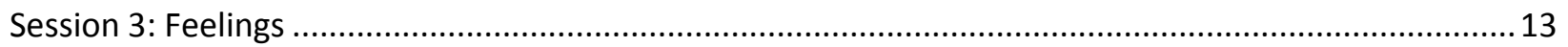

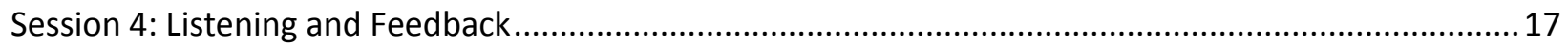

Session 5: Nonverbal Communication and Communicating with Family ................................................23

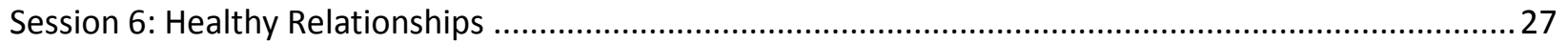

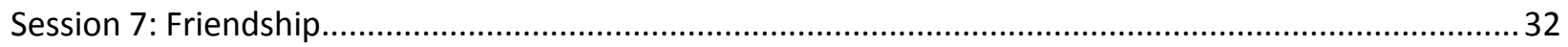

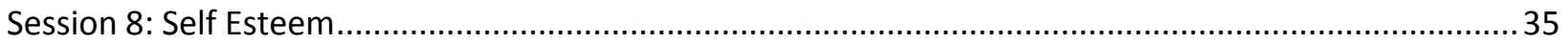

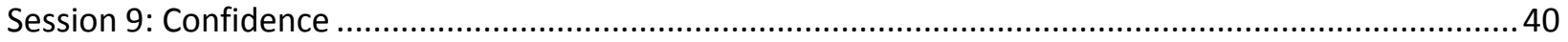

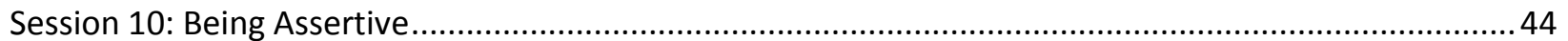

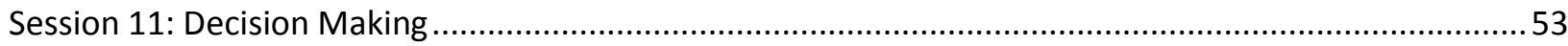

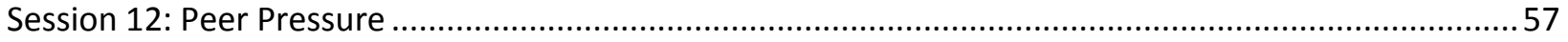

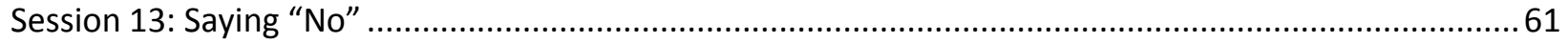

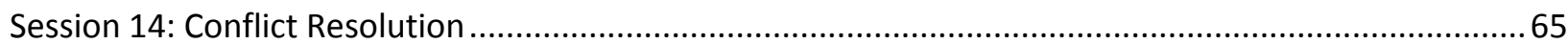

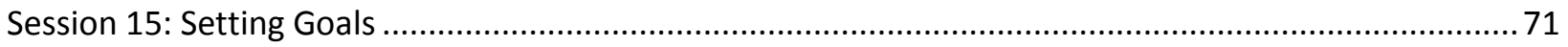

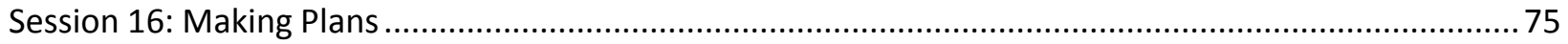

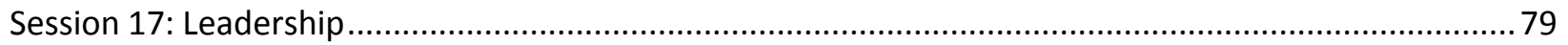

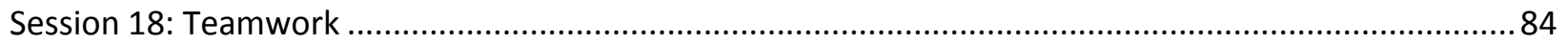

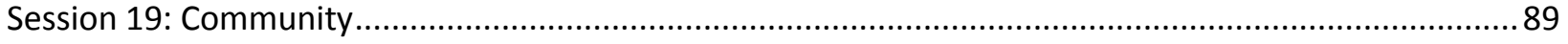

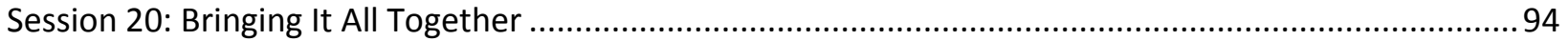




\section{Session 1: Understanding Values}

\section{Session Objectives:}

By the end of this session, girls will be able to:

- Explain the different meanings of the word "value"

- Understand the meaning of values in the context of family and relationships

- Identify some of the values that are important to them

- Feel more comfortable sharing their values with others

\section{Materials Needed:}

- Cedi notes and coins

- Flipchart or chalkboard

- Play money for each girl (or photocopies of currency notes) or marbles/pebbles

- Small cards to stick on wall

- Tape to stick cards to wall

\section{Session Outline:}

- Understanding Values (20 minutes)

- Values Voting (30 minutes)

- Life-Auction Game (40 minutes)

Total Time: 90 minutes

\section{BACKGROUND NOTES}

Values are:

- Things that are important to us

- Things we support or are against (give examples like sex before marriage, girls' right to education)

- Things we choose freely (though they are influenced by families, religious teachings, culture, friends, media)

- Things we believe in and are willing to stand up for

- Beliefs, principles, or ideas that are of worth to us and help define who we are

- Things that guide our behaviour and lives

Even young adolescents may feel strongly about personal and family values, and discussing these values may arouse emotions. Be sure that ground rules are followed at all times including confidentiality, not passing judgment on responses, and allowing everyone to participate. Emphasize that individual values differ and there are no "right" or "wrong" answers. Allow girls to express, explain, and defend their values. Encourage them to use "I" statements (expressing their own perspectives and feelings rather than making generalizations) and do not allow any put-downs (insults, jabs). 
Examples of "I" statements are:

- I believe...

- I feel...

- I do not like it when...

If there is an argument over a value-related issue, take immediate and overall control and ask each side to explain their point of view. Remind girls that people's values differ and that it is normal to disagree or agree, then move on to another topic. If confusion and dissatisfaction remain, the mentor may want to schedule a formal debate of the issue at another time.

Remember that while you are monitoring the girls to ensure that they are non-judgmental, you must be non-judgmental as well. Be aware of your own personal values, especially when controversial topics like abortion, family planning, or premarital sexual intercourse are discussed. Pay attention to your comments and body language to avoid supporting one position or another. Support girls so that they will not feel overwhelmed or subordinated by the values and opinions of their peers. Make it clear that it is normal to change one's mind based on new information or a new way of looking at an issue.

Occasionally, one or two girls will express a particular value in opposition to the rest of the group. In such a case, it is your responsibility to support the right for someone to have a minority viewpoint. Use verbal comments, touch or physical proximity to show your support, but state clearly that you support the behaviour of standing up for one's values, even if they are in the minority, rather than the position.

Whenever there is discussion about a topic and no one in the group expresses a commonly held position, remind the group of that position. You could say, "Other people might say..." and give reasons for that position.

Mentors, and other authority figures, are often asked about their own values related to various topics. It is appropriate to share some of your personal values and to discuss the values that you learned from your family, which helped you make positive decisions about professional goals or education. It is better not to share personal values related to highly controversial topics. Mentors are important figures in the lives of adolescents and can influence their values and behaviours. If asked about a controversial topic, say something like "I'm more interested in what you believe right now." If you do share personal values, be clear that the values are right for you, but not necessarily right for the girls.

\section{INSTRUCTIONS}

\section{Understanding Values (20 minutes)}

1. Place several cedi notes and coins of different values on the table.

2. Ask for two volunteers to come to the table and to choose a note.

3. Ask each person to say why she chose that particular note.

4. Thank both girls and let them return to their seats. 
5. Write the word VALUE on a flipchart or on the board and explain that in this situation, value refers to the worth of each cedi note.

6. Ask the group to give more examples of what has value. If the group only lists material or physical things, ask for examples of something that cannot be physically seen or touched but has value. (Possible answers may include things like: respect, love, honesty, friendship, kindness, hard work, and talent.)

7. List the responses on the flipchart or board and add any of your own.

8. Use the following "Presentation Notes" to explain the meaning of values to the group.

\section{PRESENTATION NOTES: VALUES}

The word "value" means different things. One meaning is the actual worth of an object or an item in cedis. Another meaning involves a more personal aspect of worth, such as how important certain beliefs or ideas are to a person. Different things are worth more or less to different people, meaning they have more or less value. The things, ideas, beliefs, and principles that are of worth to you shape your values. Our values help to define who we are and help determine the choices we make, also called our behaviour. For example: a man who values his family cares for and takes care of his wife, children, and home life; a person who values health will try to have a healthy diet, avoid behaviours that can put her or him at risk of STIs and avoids alcohol, tobacco, and other drugs; people who value education will try to study hard, get good grades, and pass examinations.

9. Ask for one or two more examples from the group.

\section{Values Voting (30 minutes)}

1. Facilitate a discussion on values by asking the following questions:

Where do you think we get our values?

What is one example of a value your family feels is very important?

What is an example of a religious value you may have been taught?

Which of your values come from your cultural beliefs?

What is a national value that may be less important in other countries?

Can you think of a value someone else has that you do not share? What is it?

2. Explain that girls will be asked to express their feelings about particular values. Designate three areas of the room as "Agree," "Disagree," and "Not sure".

3. Select five to seven of the statements below, and read each statement aloud. After each statement, ask girls to move to the part of the room to show whether they agree, disagree, or are not sure. Explain that there are no right or wrong answers and that everyone is entitled to his or her opinion.

You can earn a decent salary without finishing school.

Boys should pay the bill when a boy and girl go out.

Having a job you enjoy is more important than earning a lot of money.

It's not okay for a boy or man to cry.

Waiting to have sexual intercourse until you are an adult is a good idea.

Understanding Values | 3 
Girls should be allowed to inherit property.

Boys and girls should have equal rights.

It is important to follow traditions no matter what.

It is preferable to have male children than female children.

It is okay for a boy to have pre-marital sex, but not a girl.

In a family, the man should be responsible for financial support.

It's okay to have a child before marriage.

Drinking can help to deal with life's stresses and troubles.

Attending religious services is important for spiritual wellbeing.

People should help care for those less fortunate in wealth or health.

Adults should be respected, particularly one's parents.

Love is an important part of a happy relationship.

There's no point in planning since life is a game of chance.

4. After this exercise, bring the group together and discuss:

Did you know right away how you felt or did you have to think about each one?

Did you ever change your mind?

Did anyone else in the group influence your vote?

How did you feel about the differences in values of the group?

\section{Life-Auction Game (40 minutes)}

1. Count the number of girls and cut out about twice as many small cards to stick on the wall. On each card write something that people generally want out of life; ask the girls to call out examples. They should be both tangible and intangible things. Examples might include: handsome husband, close friends, be loved in your community, be famous, home, good job, honesty, riches and wealth, daughters, sons, car, travel, many friends, many boyfriends, clothes, alcohol, a long healthy life, happy life, career success, etc.

2. Distribute the play money/marbles/pebbles equally among the girls. Start an auction where people bid against one another for each item. Name an item and then ask what the girls are willing to pay until you get the highest price that anyone is willing to pay for that item. Once a person spends her money, she must settle for what she bought and cannot change it. Continue the auction until all the items are sold or all the money is spent.

3. Ask the girls to discuss their "purchases". Find out which items collected the most money (i.e., which were most important or valued.)

\section{Ask the Group:}

- Who managed to buy what she wanted?

- How did it feel?

- Who did not manage to get what she wanted?

- How did that feel? 
- Was anyone surprised by what they bought?

- Were there any cards that did not get bid on? Which ones?

-What does it say about these values?

- If you played again, would you use your money differently? Why?

- What did the auction tell you about what you value or what is important to you? About what you do not value?

- If there were boys playing the game do you think different things would have been bought? How? Why?

- If you were not in a group and others weren't watching you bid, would any of you spend your money differently? How? Why?

- If you died tomorrow, and everyone remembered you only for the items that you bought in this exercise, how would you feel?

\section{TAKING IT HOME}

Ask the girls to think about their three most important values and try to identify where they learned these values, or, how they came to be their values. Who in your life was important in adopting these values? If this person or these people are accessible, tell the girls to tell them about how they influenced their values.

Ask the girls to talk to their parents and other friends (who are unable to come to these sessions) about their values and tell them about their own. Ask the girls to think about what they value most as an individual and share their values with their parents and friends.

$\because$

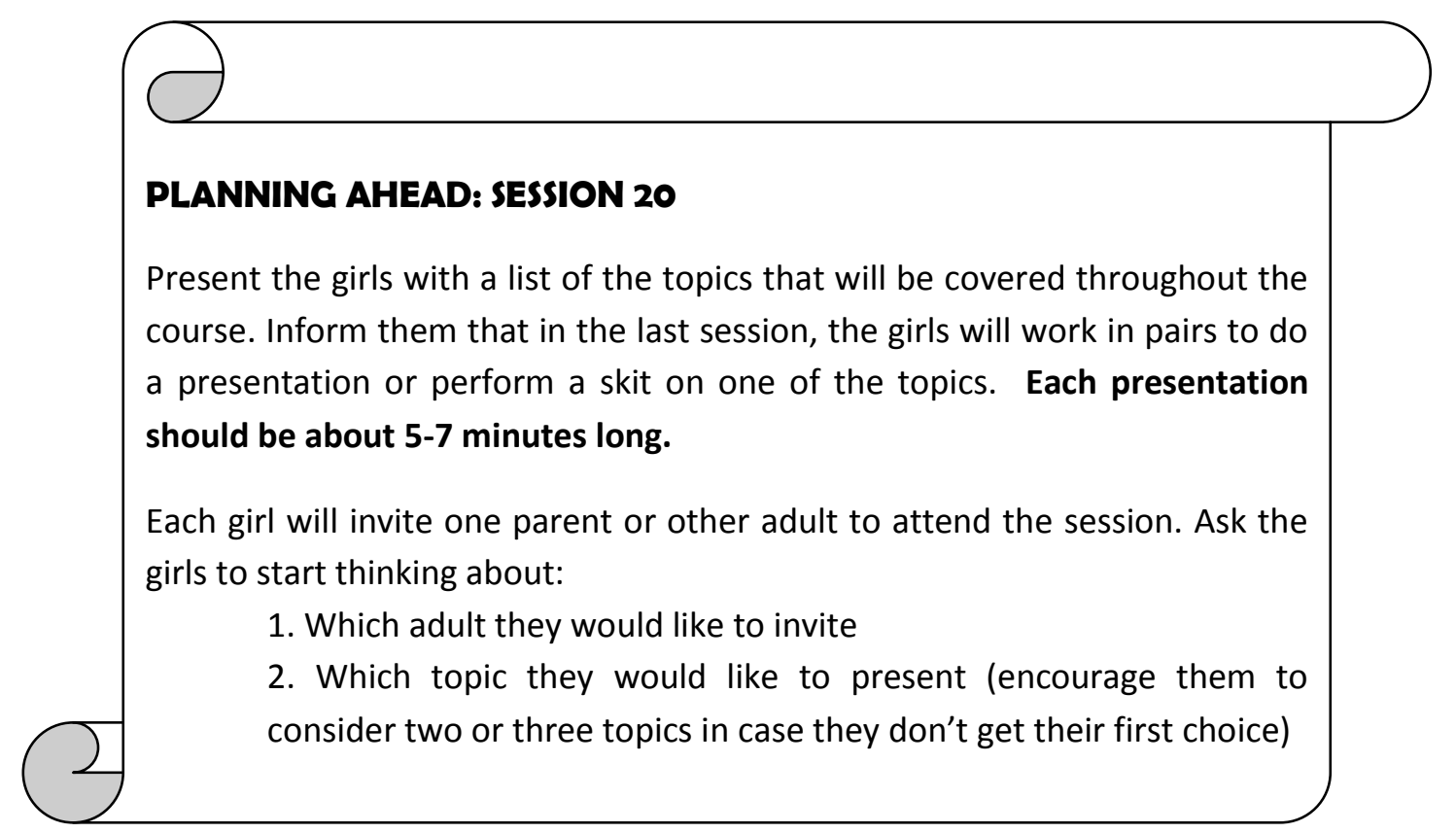




\section{Session 2: Values and Behaviour}

\section{Session Objectives:}

By the end of this session, girls will be able to:

- List core values and beliefs that can help girls achieve success

- Explain the relationship between values and behaviour

- Explore how consistent their values and behaviour are

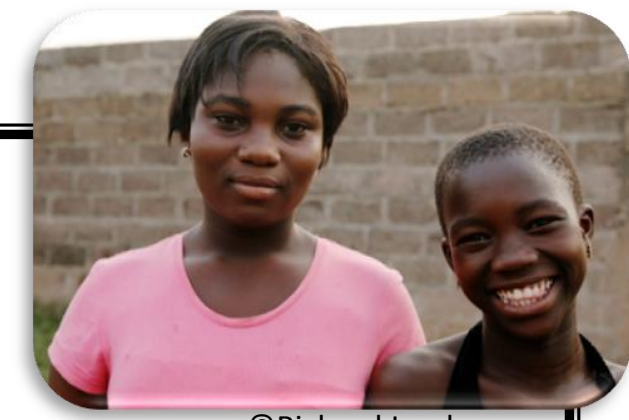

(C)Richard Lord (or are not) and why

\section{Materials Needed:}

- Values cards and Single-letters cards for Focus on the Values (p. 11) - 1 set of 16 cards per team

- Sample questions: Girls and... for Focus on the Values (p. 12)

- $\quad$ Flip chart, easel, markers

- Program journal for each girl

- Cards with Behaviours and Values

\section{Session Outline:}

- Focus on the Values (30 minutes)

- How Do Values Influence Behaviour? (45 minutes)

- Conversation Circle \& Commitment (15 minutes)

Total Time: 90 minutes

BEFORE THE SESSION: Prepare Values cards and Single-letter cards for Focus on the Values activity (p. 12).

\section{TAKING IT HOME RECAP}

Ask the girls who was able to tell someone how important they were in influencing their values. Ask for a few girls to share a little bit about their conversation - what it was like for them, and how the other person reacted.

Ask how many of the girls talked with their parents or friends about their values, and ask a few girls to share their experience.

Encourage the girls to continue talking with their friends and family about their values. 


\section{INSTRUCTIONS}

\section{RIGHT Focus on the Values (30 minutes)}

1. Mark two start lines approximately 20 metres apart.

2. Divide the girls into two equal-sized teams, Team A and Team B.

3. Ask each team to stand shoulder-to-shoulder along its start line, facing the opposing team.

4. Number each player so that Player 1 from Team A has a matching Player 1 on Team B.

5. Mark two circles at the midpoint between start lines. Label one circle Team A and the other circle Team B.

6. Scatter each team's Values cards and Single-letter cards face down - but in separate piles - in each team's circle.

7. Explain and demonstrate that:

- There are two sets of cards in each team's circle. One card is a Values card. Its match is a Singleletter card with the first letter of the corresponding value printed on it (for example, "Cooperation" is the Values card and " $\mathrm{C}$ " is its matching Single-letter card).

- When you call a player number, both players from each team race to their team's circle and turn over two cards (choose one card from each set of cards). Each player lets their team know what was uncovered by reading out loud the information printed on each card.

- If a player uncovers a matching pair, the player returns to the team line and places the matching cards aside.

- If a player uncovers an unrelated Single-letter card and Values card, the player replaces the Values card face down in the circle. The Single-letter card is left face up for the next player who may uncover its matching Values card.

- Players return to their teams after uncovering two cards.

8. Continue calling player numbers and uncovering cards until one team has only two cards left in its circle.

9. The two remaining cards should be a Values card and Single-letter card pair. The team must answer the "Girls and..." question for that value (for example, if the last two cards are Leadership and L, the team must answer the Girls and Leadership question to receive a point).

10. Replace the cards face down in the circles and continue play.

11. The game ends at your discretion.

Watch for:

- Are players reading their cards loud enough for their teams to hear? 
- Are players leaving the Single-letter cards face up when uncovered without a match?

- Are players turning Values cards face down if a match is not made?

12. Facilitate a discussion using the following questions.

- Of the values on the cards, which ones are most important to you? Why?

- Who is one person you know who lives their life by their values?

- What types of activities help nurture a girl's spirit?

\section{How Do Values Influence Behaviour? (45 minutes)}

1. Make two columns on the board, one for Values and one for Behaviours. Under the Behaviours column, write a few behaviours that could be motivated by a particular value. After you write each behaviour, ask the girls if they can think of a value that might cause someone to do that behaviour. If this is too difficult, list both the behaviours and values on the board (in a different order), and ask the girls which behaviour matches which value. Some examples are:

Behaviour: Giving money to someone in need

Value: Believe in sharing

Behaviour: Resisting peer pressure to smoke cigarettes

Value: My health is important to me

Behaviour: Studying hard and doing my homework

Value: My education is important to me

(Facilitators are encouraged to think of similar examples)

2. Explain that sometimes people have a hard time acting on their values. Name a few values and for each one, ask the group for examples of things people sometimes do that go against that value. Some examples could be:

Value: Believing that one should go to school every day

Behaviour: Skipping classes sometimes to go to the movies

Value: Believing that one should not have children before marriage

Behaviour: Having unprotected sex before marriage

Value: Believing that it's important to help out around the house

Behaviour: Not doing your chores so you can spend time with friends

(Facilitators are encouraged to think of similar examples)

3. Explain that you will read several statements, followed by a series of questions. They should not answer the questions out loud, but think about them and write notes to themselves. Each statement 
reflects a value. Questions will be about behaviours that support or ignore the value. When you have finished, the group will talk about the results.

4. Read aloud the following statements and questions (or substitute statements and questions of your own):

(a) Your health is important to you.

Do you get regular exercise?

Do you eat healthy foods?

Are you a non-smoker?

Do you avoid using alcohol and other drugs?

(b) Men and women should have equal opportunities.

Would you encourage a female friend to study advanced math or science?

Would you encourage a male friend to take sewing lessons?

(c) Making money is important

Do you want lots of money?

Would you make money by unfair means like manipulating bills and vouchers?

Would you accept a gift as a bribe?

5. Ask the girls to reflect on their answers to the questions for a few minutes and then write an ending to the following sentence:

Sometimes young people don't behave according to their values because...

6. Summarize the relationship between values and behaviour by covering the following points:

People tell others about the values that are important to them.

People do what their values tell them to do, and don't do what their values tell them not to do.

People make decisions based on their values.

People stand up for their values.

People feel guilty if they do not behave according to their values.

7. Facilitate a discussion with the following questions:

- How does it feel to stand up for your values when friends disagree with your position?

- What happens when young people's behaviour goes against their parents' values? (Answers include: parents and children argue; children may lie to parents; children and parents may avoid talking about it)

- What happens if their behaviour goes against the religious or spiritual values they were taught? (Answers include: they may stop attending religious services or avoid spiritual leaders because they feel guilty, embarrassed or angry)

- What influences people to behave in ways that are consistent with their values? Give an example. (Answers include: it feels good to follow one's values; parents and other adults reward behaviour that reflects the values they teach) 
- What influences people to behave in ways that are different from their values? Give an example. (Answers include: people may want to experiment; peer pressure; opportunity for personal gain; to rebel; to get attention)

- Will your values change or remain the same as you get older?

- If your values and behaviour are different, which should you change, your values or your behaviour?

- What are the consequences of picking bad values and behaviours?

\section{Conversation Circle \& Commitment (15 minutes)}

1. Divide girls into groups of 12 or less.

2. Ask each group to sit in a circle and discuss the following:

- What is one thing you have learned about values that is important to you?

- How or why is this important to you?

3. Ask the girls to close their eyes and make a promise to themselves-something that they will do to change their behaviour to be more in line with what they learnt about values.

4. Bring the groups back together and ask for members of each group to share what they discussed.

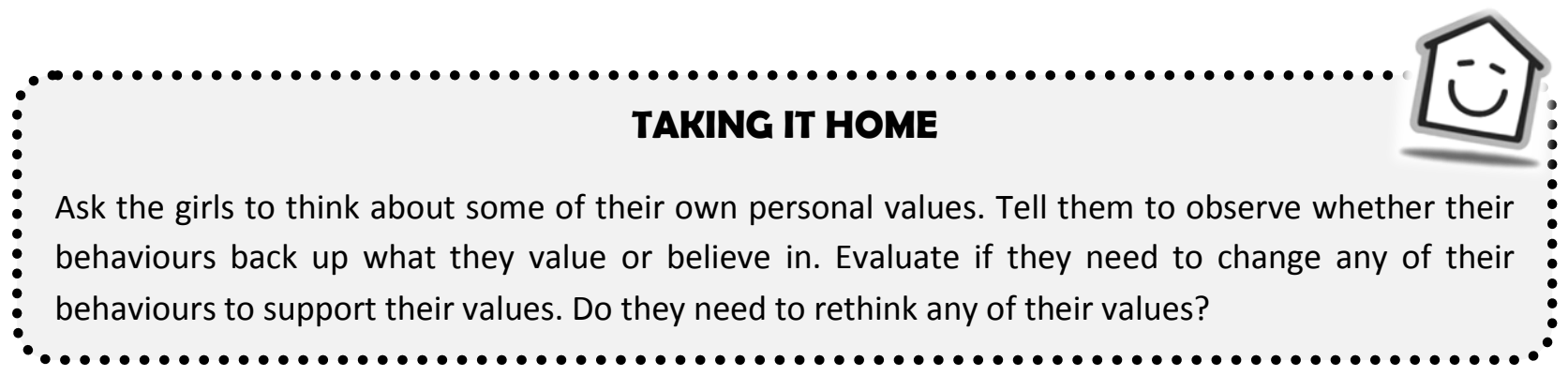


GIRLS AND COOPERATION

- Give one example of how girls cooperate in your community.

- Why is it important for girls to work together?

GIRLS AND HOPE

- Name one thing a girl can do when she's feeling hopeless

- Why is it important to have hope?

GIRLS AND INTEGRITY

- If a girl has decided not to have sex, what can she do to stay true to herself if she's being pressured?

- How can girls help each other live according to their values?

GIRLS AND LEADERSHIP

- Give an example of how girls can lead in your school, community or country.

- What can a girl do if someone believes that she is unable to lead effectively?

GIRLS AND DEDICATION

- What kinds of activities are girls in your community dedicated to doing?

- How can you tell if a girl is dedicated to her goals?

GIRLS AND RESPECT

- How can you tell if a girl respects herself?

- What kinds of things do people say and do to disrespect girls?

GIRLS AND ENTHUSIASM

- What kinds of activities or interests are girls in your community enthusiastic about?

- How can you support girls in the areas that interest them?

GIRLS AND NURTURING

- Name some practical ways you can nurture and support your girl friends.

- What can a girl do to nurture (take care of) herself? 


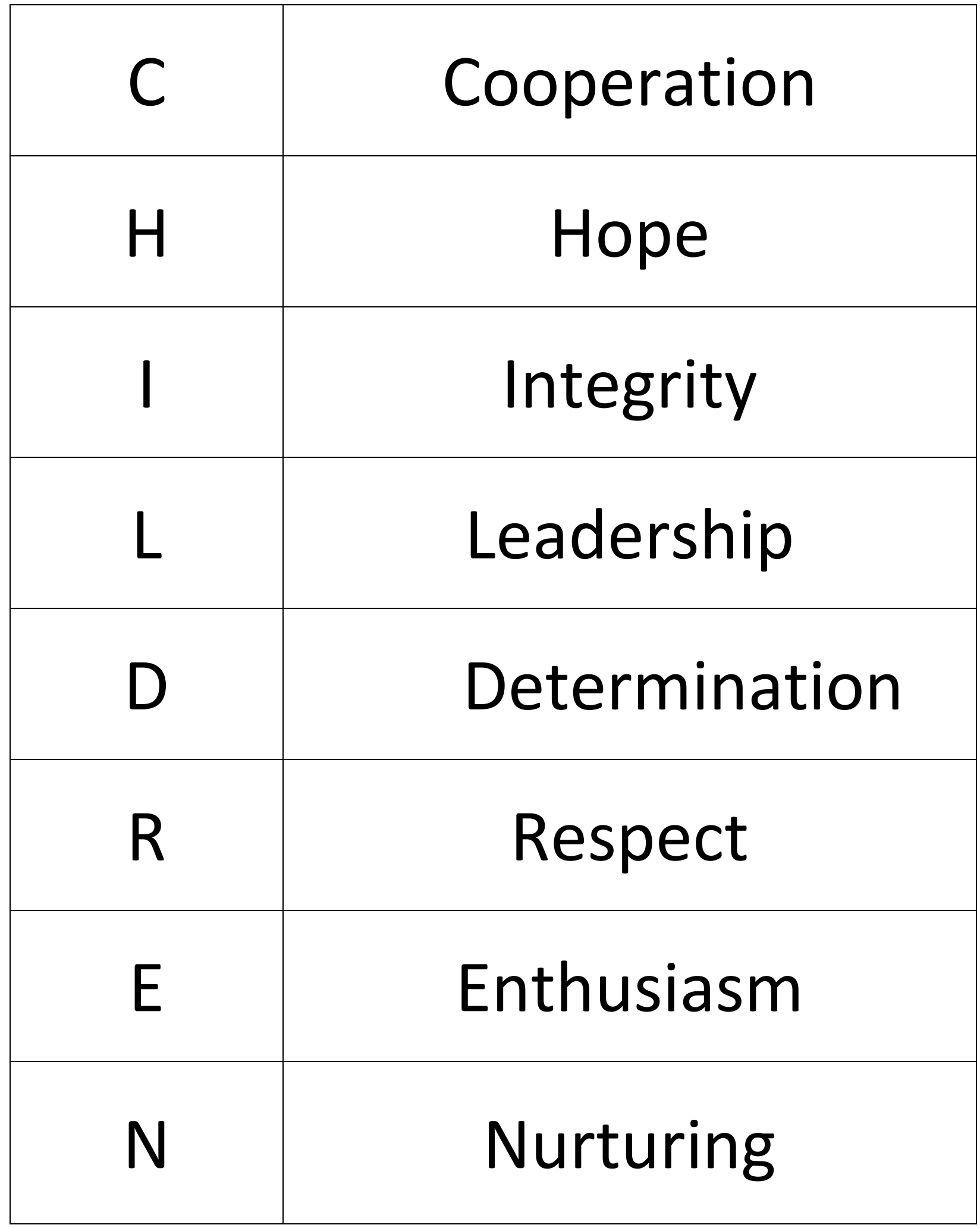




\section{Session 3: Feelings}

Session Objectives:

By the end of this session, girls will be able to:

- Develop an awareness of the broad range of feelings that can be experienced in life

- Identify which feelings they personally experience easily

- Examine ways of understanding feelings

- Identify the relationship between feelings, perceptions, and beliefs

- Explore how to understand and manage our feelings

\section{Materials Needed:}

- Flip chart, easel, markers

- Program journal for each girl

- "Describing Feelings" handout for each girl (p. 16)

\section{Session Outline:}

- What Feelings Do I Have? (60 minutes)

- What Do I Do with These Feelings? (30 minutes)

Total Time: 90 minutes

\section{TAKING IT HOME RECAP}

Ask for a few volunteers to share what they observed about their values and behavior since the last session. Did any of the girls decide to change their behavior to better support their values? Did any of them rethink any of their values?

\section{INSTRUCTIONS}

\section{What Feelings Do I Have? (60 minutes)}

1. Brainstorm onto a flip chart a list of words that describe feelings (feeling words). If it helps the group, use the alphabet as a way of exploring the broad range e.g. $A=$ afraid or angry, $B=$ bold.... (See worksheet for help). When the group has exhausted its list, pass the "Describing Feelings" to each person and give them a moment to look through the broad range of feelings.

2. Split the girls into groups of 3 and let each small group choose a feeling that they would like to develop a small role-play around. Ask each small group to try and identify a feeling that the three girls experience most often. The role-play should demonstrate clearly the expression of that feeling. 
3. After giving the group a few minutes to practice, ask for 3-5 groups to volunteer to perform their roleplay for the group. After each performance, ask the rest of the group:

- What feeling was being expressed?

- In what ways was it expressed?

4. Facilitate a discussion by asking the following questions.

- How did the girls feel about there being so many feelings available?

- Which feelings are easy to express?

- Which feelings are difficult to express?

5. Clarify with the group what are positive, negative and neutral feelings. Ask:

- When do they have positive feelings? e.g.: When the schoolteacher gives them praise; or if they help someone to cross the road

- Is it always possible to have positive feelings?

- Are negative feelings bad to have? Why or why not?

6. Explain that negative feelings are not bad but they are an important way of expressing what may have, or still is, hurting us. Congratulate the group for examining their feelings.

\section{What Do I Do With These Feelings? (30 minutes)}

1. Ask the group to respond to the following statements

- If a person's team lost a game. She/he feels ...

- If a person is given a gift. She/he feels ...

- If a person is called names. She/he feels ...

Encourage several responses for each statement and point out that people can have different feelings to the same situation. Unlike physical pain or deprivation, which has automatic physical responses, our responses to many events and circumstances in our lives can vary greatly according to our perceptions and beliefs about a situation.

2. Invite the girls to explore their feelings to the following situations.

\section{Scenario 1:}

a. You and your classmate were supposed to work on a class project together. On the day that it is due you discover that your classmate did not finish her part of the project so both of you get a low grade from the teacher.

Ask girls to list their feelings on a flip chart. Usually the group responds naming feelings such as annoyance, anger, irritation, and frustration.

Now inform the group that:

b. You learn that your classmate's mother has recently been involved in a serious accident and she has been spending all her time caring for her and helping the rest of the family. Now how do you feel about the situation? 
Ask girls to name these feelings. Usually the group responds naming feelings such as guilt, sympathy, empathy, embarrassment.

\section{Scenario 2:}

a. You walk down the street and you see your boyfriend talking with a girl you haven't seen before and smiling and laughing with her. Write feelings on flipchart.

b. You discover your boyfriend's cousin is visiting from out of town and he was showing her around town. How do you feel now?

\section{Scenario 3:}

a. You walk down the street and you see your younger sister and her friend talking with a boy you haven't seen before and smiling and laughing with him. Write feelings on flipchart.

b. You discover your sister and her friend were only talking to a boy who had recently enrolled in their class. How do you feel now?

5. Facilitate a discussion by asking the following questions.

- What has changed from scenario "a" to scenario " $b$ " in each example?

- Why are your feelings different in the different examples?

- Can you think of other situations where your feelings or reactions to a situation might have been different if you had known more information about a situation?

\section{TAKING IT HOME}

Tell the girls to try to notice their feelings and reactions to different situations and to think about what beliefs and perceptions they hold and how they influence feelings about a situation. Do your feelings change if your perceptions and beliefs change?

Ask them to observe how they and others around them express their emotions during the next week. What are some useful ways of expressing different feelings to others that are clear and not hurtful to others? What are others things you observe that are not so useful? 


$\begin{array}{lll}\text { afraid } & \text { excited } & \text { nervous } \\ \text { amused } & \text { exhausted } & \text { peaceful } \\ \text { angry } & \text { fine } & \text { pleasant } \\ \text { assertive } & \text { fond } & \text { powerless } \\ \text { awful } & \text { friendly } & \text { proud } \\ \text { bored } & \text { frustrated } & \text { sad } \\ \text { calm } & \text { furious } & \text { scared } \\ \text { caring } & \text { glad } & \text { shy } \\ \text { cheerful } & \text { happy } & \text { strong } \\ \text { cherished } & \text { hateful } & \text { terrified } \\ \text { confident } & \text { ill } & \text { timid } \\ \text { confused } & \text { insecure } & \text { unhappy } \\ \text { courageous } & \text { irritated } & \text { unhealthy } \\ \text { curious } & \text { jealous } & \text { unsure } \\ \text { delighted } & \text { joyful } & \text { unwanted } \\ \text { depressed } & \text { loving } & \text { upset } \\ \text { disappointed } & \text { lucky } & \text { warm } \\ \text { disgusted } & \text { mad } & \text { weak } \\ \text { doubtful } & \text { miserable } & \text { worried } \\ \text { embarrassed } & \text { misunderstood } & \text { worthless }\end{array}$




\section{Session 4: Listening and Feedback}

\section{Session Objectives:}

By the end of this session, girls will be able to:

- Understand how easy it is to hear or share information incorrectly

- List good listening skills

- Explore the role of feedback in communication and how this influences behaviour change

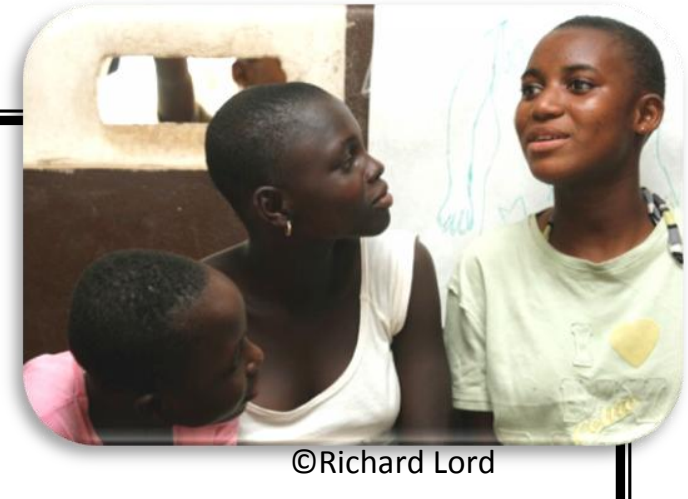

- Know how to give feedback effectively

\section{Materials Needed:}

- $\quad$ Flip chart, easel, markers

- "Listener" index cards with positive and negative listening behaviors

- "Speaker" index cards with scenarios to talk about

\section{Session Outline:}

- Whisper Circle (15 minutes)

- Listening Skills (45 minute)

- Feedback (45 minutes)

Total Time: 105 minutes

BEFORE THE SESSION: The facilitator should prepare index cards with instructions for the listeners. Write different negative listening behaviours on some of the index cards (two behaviours on each card) and different positive listening skills on the other index cards, two per card. Refer to handouts: "Negative Listening Behaviours" and "Positive Listening Skills" (p. 22).

\section{TAKING IT HOME RECAP}

Ask the girls what they observed about their feelings, and how their beliefs affect their reactions to different situations. Did their feelings change if their perceptions and beliefs changed?

Ask the girls what they observed about how they and others around them express their emotions. What are some useful ways of expressing different feelings to others that are clear and not hurtful to others? What are others things they observed that are not so useful? 


\section{BACKGROUND NOTES}

Communication is the process of sending and receiving information or thoughts through words, actions, or signs. People communicate to share knowledge and experiences. Communication is a skill and forms the basis of all relationships. The quality of communication often determines the quality of a relationship. People communicate to give information, express feelings, and solve problems or arguments.

Non-verbal communication or body language gives meaning to what is said and includes tone of voice, facial expressions (smiling, frowning, etc.), eye contact, body position (sitting, standing, pacing, leaning forward or backward), touch, and actions. Body language can influence communication negatively or positively.

Verbal communication is when one person talks and others listen and react. The conversation can be informative, in the form of questions, a negotiation, statements, instructions, or a story. In relationships communication is usually informal. Communication misunderstandings and problems can happen when one person talks for too long, speaks too softly, interrupts the speaker, does not listen carefully, or when there are loud noises in the background or other distractions.

Listening carefully is essential for effective communication. Many times the listener is busy thinking about what they are going to say and does not pay close attention to what the speaker is saying. This can cause misunderstanding and confusion. It is important to listen closely to everything that is said without interrupting and then react afterwards.

\section{INSTRUCTIONS}

\section{Whisper Circle (15 minutes)}

1. Ask girls to sit or stand in a circle.

2. Explain to the group that you are going to play a game. Explain the rules of the game before you start. These are that:

a. Each person must tell the story they hear to the person sitting on their left.

b. Girls must speak clearly so that the person sitting on their left can hear, but not so loudly that others can hear.

c. Girls are not allowed to repeat any part of the story or to tell the story to the same person twice.

3. Check that girls understand themselves and then start the game. Think of a story that is a bit complicated and perhaps involves several characters, but do not make it too hard to remember. The story should be very brief, about 10-15 seconds.

4. When the last person has received the story ask her/him to repeat what $\mathrm{s} /$ he heard. 
5. Check what other girls heard and compare that with the original story that you told.

6. Discuss briefly where communication could have gone wrong and encourage girls to share what they have learnt from the activity.

\section{Listening Skills (45 minutes)}

1. Form groups of three by having girls count off " 1 ", " 2 " and " 3 ". All "ones" will be speakers, while "twos" and "threes" will be listeners.

2. Give each speaker an index card with a scenario on it. The speakers will talk to the listeners about their scenario for 3 minutes. Instruct the speakers to talk to the listeners like they would talk to a close friend. Some example scenarios are:

- Your older sister wants you to do her chores on Friday so that she can go out with her friends, but you think this is unfair.

- You had a fight with your best friend, and now she isn't talking to you.

- You just found out that you got top marks on your math test last week.

- You went to your cousin's wedding yesterday and had a nice time with your family.

- You got a bad grade on your English homework, and you are worried that you might not pass the class.

(Facilitators are encouraged to think of additional examples)

3. Number "twos" will be the negative listeners and number "threes" will be the positive listeners, but do not tell the listeners or the speakers this. Simply give the number "twos" one of the index cards with negative listening behaviours and the number "threes" one of the cards with instructions for positive listening skills. Instruct the speakers to start talking. Instruct listeners to start listening to the speaker and after a little while, begin to do what it says. Tell "ones" that they have to speak for 3 minutes.

4. After a few minutes, bring the group together and ask the speakers how they felt about their friends' listening skill. Ask the speakers which listeners made them feel most "listened to". Have those listeners read the instructions on their index cards. List these positive listening behaviours on a flip chart and add other listening skills from the list below. This way the group will make their own list of positive listening behaviours. Do a role play with two of the group members and repeat the positive listening behaviour skills. Ask the group to identify which of the positive listening behaviours were demonstrated.

5. Next, ask speakers which listeners made them feel the least "listened to". Be clear that the bad listeners were simply following instructions. List the negative listening behaviours on a flip chart. The group will thus have a list of negative listening skills.

6. Facilitate a discussion by asking the following questions.

- What makes one a good listener?

- When have you used negative listening skills?

- What happened and what was the outcome?

- When have you used positive listening skills?

Listening and Feedback | 19 
- What happened and what was the outcome?

- Which of these positive listening skills can be used practically in life?

\section{Feedback (45 minutes)}

1. Ask for six volunteers to perform the following scenes. Give each pair a copy of their assigned scene and allow them a few minutes to practice. Then ask the actors for Scenes 1 and 2 to present their scene.

\section{Scene 1}

Two friends meet to go to a party. One does not like the other's clothes and says so. S/he says something like, "What on earth are you wearing?" or "Where did you get those? They are so...uncool!" The other person looks very unhappy and asks, "What's wrong with my clothes?" but the first speaker just laughs and walks off.

\section{Scene 2}

A person is practicing a song for a show that is coming up, when one of her/his friends drops in to see how things are going. At the end of the practice the person singing asks her/his friend what $s /$ he thought of their song and singing. The second person replies "The song is nice but not the way you sing it. Your voice does not sound right!" The first person does not know what to say and just stands there as the second person walks off.

*Note: Do not show Scene 3 until after the discussion, at the place below where it is indicated to do so.*

\section{Scene 3}

A person has been asked to give a short talk to a group of 12 year olds on "Staying away from drugs." $\mathrm{S} /$ he has asked a friend to read through it and say what $\mathrm{s} /$ he thinks. The feedback is given in a way that does not hurt the other person's feelings, and helps the person improve their talk. For example, the friend smiles and says, "I really like the point you made about marijuana, but at first I had a hard time understanding that "cannabis" meant marijuana. Maybe you could explain that earlier in your talk." The first person says, "Thanks, that's easy to do." In this way, s/he shows that s/he understands the feedback and appreciates it.

\section{Ask girls to describe what they saw happen in Scenes 1 and 2.}

3. Ask them to break into groups of three or four and discuss, "What could have been done differently in each scenario?"

\section{After five minutes ask each group to share its views.}

5. List key words that come out on flipchart paper.

6. Ask the girls to watch closely and then present Scene 3. 
7. Ask for general comments on Scene 3 and the difference between that and the first two scenes.

8. Facilitate a discussion on how feedback can be helpful or hurtful by asking the following questions:

- When can feedback be helpful and when can it be hurtful?

- When is it okay or not okay to give somebody feedback?

- What are some ways to make sure that negative feedback is helpful, not hurtful?

- What is the difference between feedback and criticism?

9. At the end ask if there are any comments or questions and discuss these.

10. Summarize and highlight the following points.

- Feedback is when we give someone our opinion about something the person said or did. It is usually given when asked for or expected.

- Positive or negative feedback is given to help someone improve.

- It is good to give some positive feedback before sharing more negative feedback.

- Feedback is not helpful if it does not help someone improve, or if it cuts a person down.

- Remember that feedback does not mean criticizing someone. It is helping someone to understand how they are seen through the eyes of someone else, so that such a person can get to know herself or himself better and become more aware of her/his behaviour.

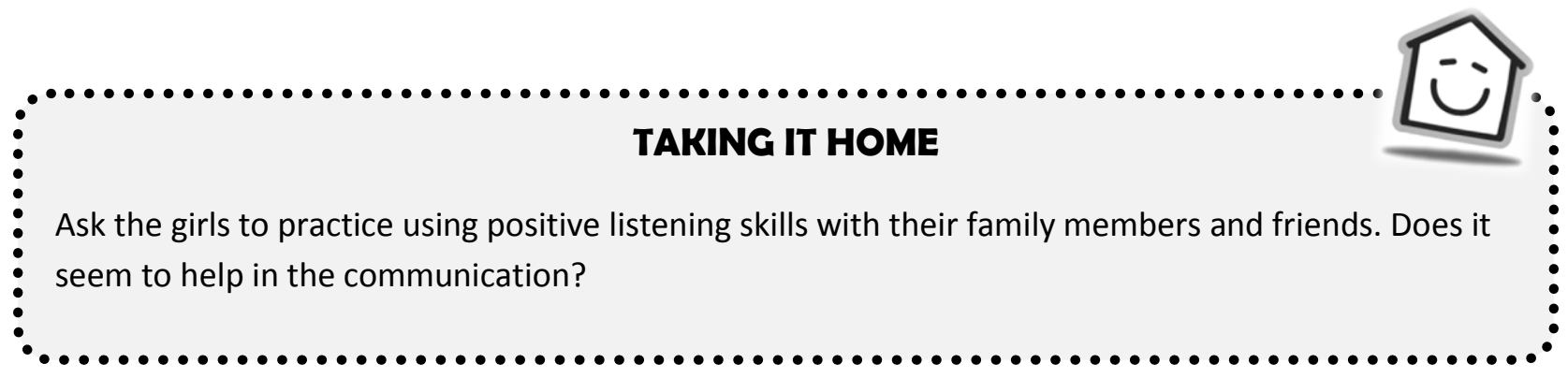


Negative Listening Behaviours

1. Give advice even if you aren't asked for it - say something like "You should" or "If I were you...."

2. Interrupt the speaker while she or he is talking.

3. Try to top the speaker's story with a better one of your own.

4. Put the speaker down by criticizing her or his behaviour, saying things like "That's dumb" or "Why would you do that?"

5. Change the subject to something unrelated to what the speaker is talking about.

6. Lean over and start whispering to someone else while the speaker is talking.

7. Listen carefully at first, then begin to look bored: gaze around the room, sigh, look at your watch, roll your eyes.

8. Disagree with the speaker: each time she/he says something, challenge it and say what you think she/he should be doing.

9. Start writing, reading, drawing or scribbling.

\section{Positive Listening Skills}

1. Give the speaker your full attention. Stop doing other things, remove distractions such as television and turn to face her or him.

2. Lean towards the speaker.

3. Make eye contact with the speaker, unless that would be rude in your culture.

4. Nod or shake your head in response to the speaker's comments.

5. Make verbal responses that let the speaker know you are listening, such as "uh-huh," "yes" or "go on."

6. Change your facial expression to reflect the appropriate emotion, such as concern, excitement, fear and so on.

7. Check out the meaning of the speaker's message - say what you think she/he is saying and ask if that is correct.

8. Try to figure out what the speaker is feeling and check to see if you are correct.

9. Do not interrupt unless time is an issue and you have to be somewhere else or do something. In that case, apologize and ask to finish the conversation at another time.

10. Ask questions to clarify what the speaker is saying. For example, "Are you saying...?" or "I'm not sure I understand, could you tell me more about that?"

11. Compliment the speaker with statements like "I really liked the way you handled that" or "It sounds like you are really trying to deal with this."

12. Reflect the speaker's message back - say something like" I think you are saying....." or" It sounds like...." 


\section{Session 5: Nonverbal Communication and Communicating with Family}

Session Objectives:

By the end of this session, girls will be able to:

- Understand how easy it is to hear or share information incorrectly

- List methods of nonverbal communication

- Explore the role of feedback in communication and how this influences behaviour change

- Know how to give feedback effectively

\section{Materials Needed:}

- Flip chart, easel, markers

- Paper and pen or pencil for each group

\section{Session Outline:}

- Line Ups (20 minutes)

- Non-Verbal Communication (30 minutes)

- Communicating with Parents and Family Members (40 minutes)

Total Time: 90 minutes

\section{TAKING IT HOME RECAP}

Ask the girls to share their experience using positive listening skills with their family members and friends. Did it seem to help in the communication?

Encourage the girls to continue practicing positive listening skills in their daily life.

\section{INSTRUCTIONS}

\section{RIGHT Line Ups (20 minutes)}

1. Divide the girls into groups of 6-10.

2. Tell the girls that this is a game that requires them to use different forms of communication.

3. Explain and demonstrate that:

- You will ask the girls to form straight lines in a specific order (for example, from tallest to shortest, from youngest to oldest, alphabetical by first name, alphabetical by last name, etc.)

- The girls will have to work together to form the line as quickly as possible. 
4. When the girls become comfortable with forming the lines, challenge them to form new lines without speaking. For example "Get into a line from smallest hands to largest hands without making a sound."

5. The game ends at your discretion.

Watch for:

- Are the girls organizing themselves quickly?

- Is every girl participating?

- Are the girls using gestures to communicate when they are not allowed to speak?

6. Facilitate a discussion using the following questions:

- What did you find challenging about this activity?

- How did you organize yourselves when you weren't allowed to speak?

- When else in life do you have to use different ways of communicating?

- What are some ways of communicating when you cannot use words?

- What can you do to communicate with someone who is mute (cannot speak) or has a hearing impairment (cannot hear)?

\section{Non-verbal Communication (30 minutes)}

1. Divide girls into groups. Assign each group feelings/actions from the following list and ask them to practice silently acting them out without letting the other groups see:

Anger
Shyness
Rejection
Excitement
Satisfaction
Disappointment
Fear
Exhaustion/tiredness
Worry/stress
Regret
Happiness
Envy

2. Ask each group to act out their feelings/actions without speaking. Ask the other girls to guess what they are feeling.

3. After each group has acted out their emotions, facilitate a discussion about non-verbal communication using the following questions:

- What are other gestures or expressions that we commonly use?

- Why do people use nonverbal communication instead of expressing themselves verbally? 
- Is it possible not to use nonverbal communication?

- Can non-verbal communication contradict verbal communication? (for example, a person is visibly upset but says she is "fine.")

\section{Communicating with Parents and Family Members (40 minutes)}

1. Ask the girls who, besides their friends, they feel most comfortable sharing various issues with. It could be someone in their family or outside their family.

- If you have a problem, who would you go to? Why?

- When you have achieved something, whom do you go to, to share the good news? Why?

2. Divide the group into 6 smaller groups and assign the following tasks to each group:

Group 1: list all the issues you feel comfortable discussing with your older male relatives, like your father, grandfather, or uncles

Group 2: list all the issues you feel comfortable discussing with your older female relatives, like your mother, grandmother, or aunts

Group 3: list all the issues you don't feel comfortable discussing with your older male relatives, like your father, grandfather, or uncles

Group 4: list all the issues you don't feel comfortable discussing with your older female relatives, like your mother, grandmother, or aunts

Group 5: list all the issues you feel comfortable discussing with your older sibling

Group 6: list all the issues you don't feel comfortable discussing with your older sibling

3. Paste all the responses on the wall. For each of the three types of family members, make two columns, one for issues the group is comfortable discussing and one for the issues the group is not comfortable discussing. Take one list at a time and ask the group why they feel comfortable or uncomfortable discussing the issues they listed.

4. Ask the group to split up into pairs for a role-play. One girl will play the older male relative, older female relative, or older sibling of the other girl. Instruct each pair to pick one of the uncomfortable issues listed on the wall, and practice discussing it for a few minutes. Then have the pairs switch roles and pick a different issue to discuss.

5. Bring the group back together and facilitate a discussion by asking the following questions.

- How did it feel to practice talking about some of the uncomfortable issues?

- What are some things you can do that would make it easier to talk about these issues in real life?

- What are some ways we can promote good communication between young people and their parents? 


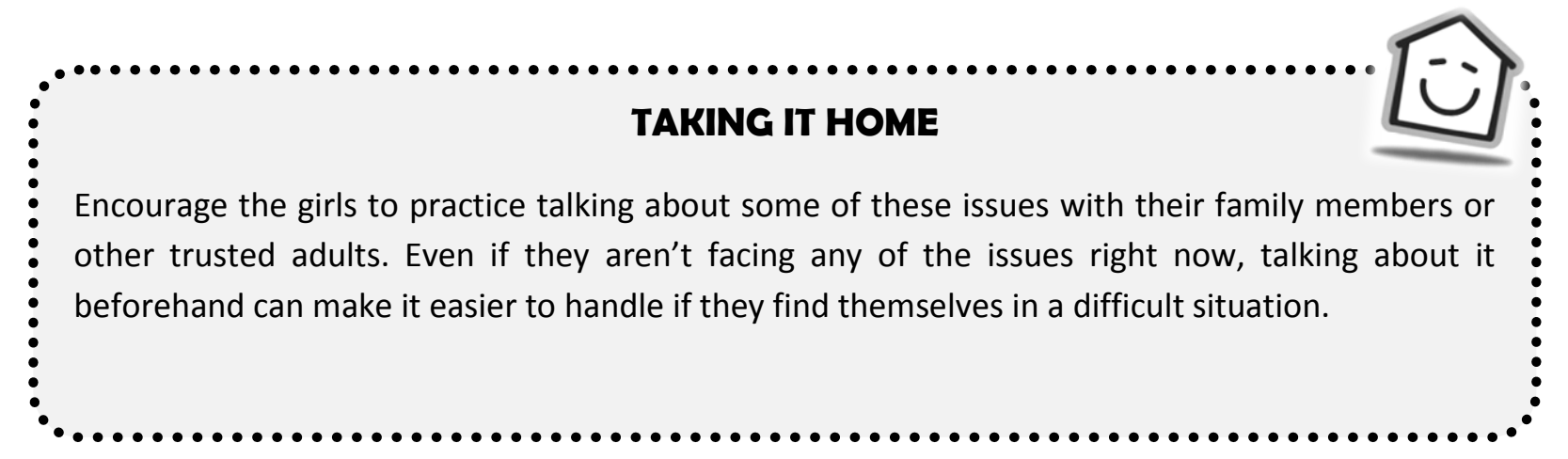




\section{Session 6: Healthy Relationships}

\section{Session Objectives:}

By the end of this session, girls will be able to:

- Identify positive and negative factors that influence relationships and how to deal with these

- Discuss how to build positive relationships

\section{Materials Needed:}

- $\quad$ Flip chart, easel, markers

- "The Ship" poster (p. 31)

- Sticky tape

- Paper and pen or pencil for each group

Session Outline:

- The Ship (60 minutes)

Total Time: 60 minutes

\section{TAKING IT HOME RECAP}

Ask a few girls to share their experience talking about tough issues with their family or other adults. Was it as difficult as they thought it would be?

Encourage the girls to continue talking about these issues. Emphasize that the more they talk about them, the easier it will get.

\section{INSTRUCTIONS}

\section{The Ship (60 minutes)}

1. Start with an open discussion on the following questions:

- What is a relationship? (Make sure the girls understand that the word relationship is not always romantic, and that it can mean any kind of connection or interaction with others.)

- What are the different types of relationships that young people find themselves in?

- Why do people get into relationships?

2. List the responses on flipchart paper.

3. Display "The Ship" Poster. A full-page version of the poster that you can use or recreate is located at the end of this session (p. 31). 


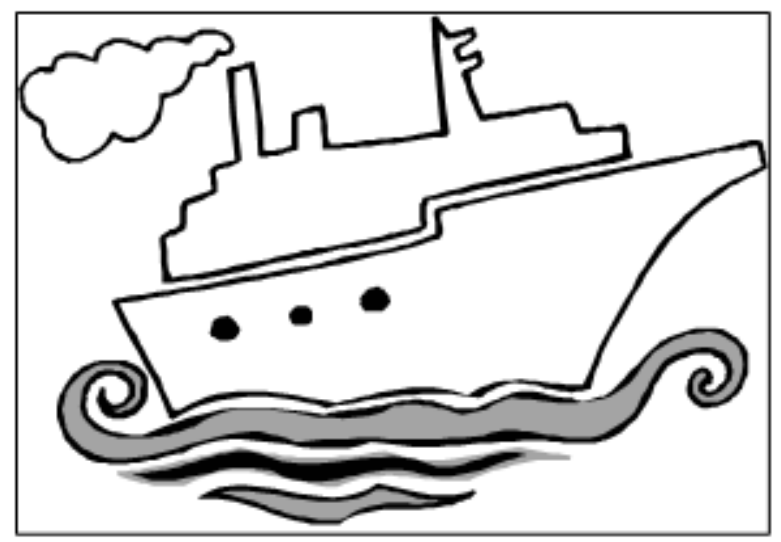

4. Point out that just as there are certain things that keep a ship afloat and moving (calm seas, fuel, a solid hull or base), there are certain things needed to keep a relationship afloat.

5. Ask for an example of something that is necessary for a strong or healthy relationship (e.g. respect) and write it on the hull or base of the ship.

6. Also point out that there are certain things that can ruin a relationship, just as stormy seas or a bad storm can sink a ship. Ask for an example (e.g. dishonesty) and write it in the water beneath the ship.

7. Divide the girls into six groups and give each group a sheet of flipchart paper with one of the following headings written at the top.

Explain that each heading refers to a type of relationship.

- $\quad$ Peers \& Friends

- Romantic

- Parents (or other adult relatives)

- Siblings

- Teachers

- Community

8. Tell girls that each group should do the following:

a) Draw a picture of a ship in the water.

b) Identify at least five things that help make their particular type of relationship successful and write these on the hull or base of the ship.

c) Identify at least five things that could damage or destroy the relationship and write these in the water beneath the ship.

d) Hang the flipchart paper on the wall when they are finished.

e) Spend no more than 15 minutes on this activity. 
9. When all the groups are finished, allow some time for them to move around and look at each other's ships.

10. You can use any of the following "Presentation Notes" to elaborate if needed.

\section{PRESENTATION NOTES}

\section{$\underline{\text { Respect }}$}

Respect is shown through attitudes and behaviour. The other person must feel valued, worthwhile, and important. Negative criticism, name-calling, and ridiculing are destructive. Useful ways to show respect include being there when needed, listening carefully to what is said, and responding appropriately.

\section{Empathy}

This means trying to understand another person's position, that is, trying to see situations from the other person's point of view. This shows a deeper understanding, particularly if communicated back to the other person using different words. Empathy is different from sympathy.

\section{$\underline{\text { Genuineness }}$}

Being genuine involves being yourself and having positive self-esteem. Genuineness is shown if verbal and non-verbal behaviour give the same message. Being genuine involves being yourself and having positive self-esteem.

\section{$\underline{\text { Values and Attitudes }}$}

Successful friendships/relationships are often based on the individuals having similar values. Two people will continuously be in conflict if their values about most things differ. Values can change over time, owing to changing circumstances, etc. This may have an effect on a relationship. Pressure to change values may jeopardize a relationship. If virginity before marriage is valued, for example, then pressure to become sexually active will harm the relationship.

\section{Communication}

Humans communicate verbally and non-verbally. Verbal communication is talking. Non-verbal communication, also known as body language, is shown by listening, smiling, frowning, nodding, body posture, etc. Communication reveals how one individual feels about another. Most people tend to spend more time talking than listening. Listening is a skill that takes time to develop and needs to be practised.

11. Encourage a brief discussion around the question, "Which qualities do you think are the most difficult to find in a relationship?"

12. Ask if there are any questions or comments and address these. 
13. Summarize and highlight the following points.

- No two people are the same. We therefore need to compromise and understand each other's differences for relationships to be successful.

- Many people practise negative behaviours in their relationships.

- Respect and communication are two important factors needed to build a good relationship. (Here you can check what girls remember about communication from Sessions 4 and 5.)

- We have to be honest with ourselves and those we have a relationship with. We should say when things are going right and when we are unhappy about something.

- We need to assess our relationships and decide whether they are good or bad for us.

- Everyone deserves good relationships. Each of us has a clear idea of what we would like in a friend or partner, and we must be able to hold onto that.

- Apart from the five qualities discussed in this activity, there are several other qualities that make a relationship special. Remember that the best relationships result from each person working hard at giving the best of themselves at all times. Many relationships are far from perfect so we need to keep working at those that are important to us, especially those with our peers.

\section{TAKING IT HOME}

Ask the girls to observe their relationships, thinking about the things that help keep relationships "afloat" and the things that make them "sink." Do they have any relationships that seem to be sinking, and what can they do to keep them afloat? 


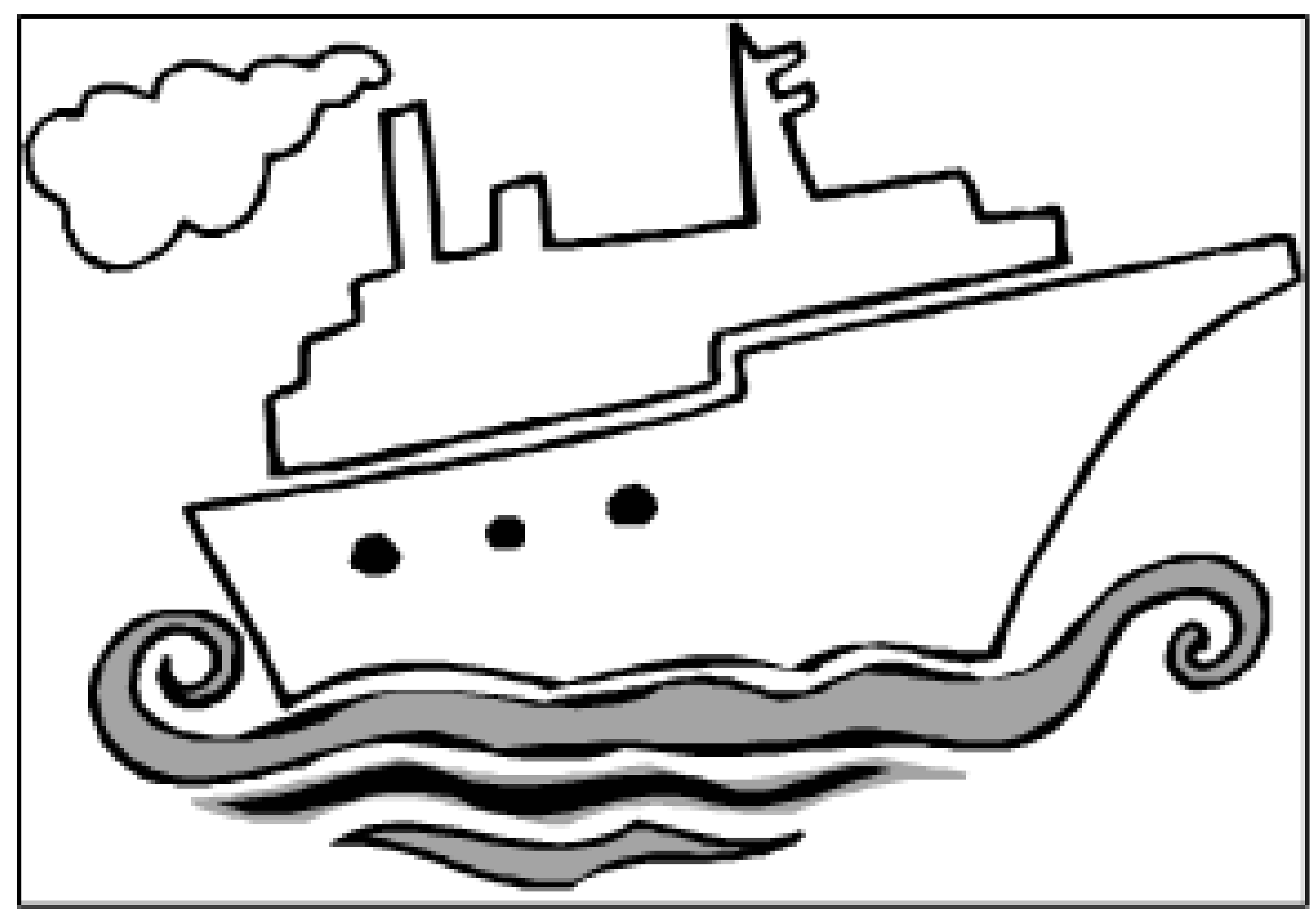

Healthy Relationships | 31 


\section{Session 7: Friendship}

\section{Session Objectives:}

By the end of this session, girls will be able to:

- Define friendship

- Determine the qualities of a good friend

- Determine the limits of friendships

\section{Materials Needed:}

- Index cards for each girl

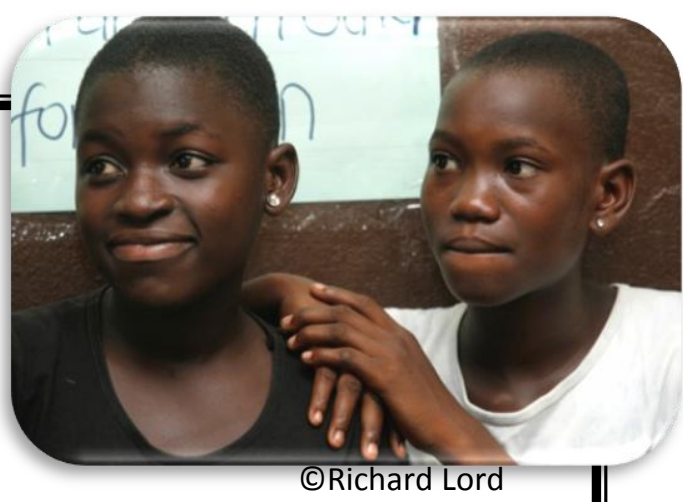

- Slips of paper with SCENARIOS for Limits of Friendship (p. 34)

- Container for slips of paper

\section{Session Outline:}

- Qualities of a Good Friend (40 minutes)

- Limits of Friendship (40 minutes)

Total Time: 80 minutes

\section{TAKING IT HOME RECAP}

Ask for a few volunteers to share what they observed about their relationships. Were they able to use what they learned to boost any "sinking" relationships?

\section{Qualities of a Good Friend (40 minutes)}

1. Ask everyone to think of a person whom they call a good friend, maybe even a best friend. Give each person a card and write the following on a flip chart:

“ is my good friend because..."

(Name of friend)

2. Have girls copy on their cards and complete it, filling in the name of a close friend and a characteristic or quality that makes a good friend. Reassure the girls that no one but you will see the cards.

3. After a few minutes collect the cards and put in a container. Explain that you will read each one, omitting the name of the friend but reading aloud the qualities mentioned. As you read each card, get someone to write a list of qualities identified. 
4. When you have gone over all the cards and the list is complete, divide into small groups of four and five and give them the following task:

- Work together to list (and agree on) 5 qualities you want in a close friend.

- Rank the qualities " 1 " for the most important and " 5 " for the least important.

5. Allow about 5 minutes, then ask each group to share their choices and rankings.

6. Facilitate a discussion by asking the following questions.

- Was it easy or difficult to decide on which 5 qualities were most important? Why?

- How did your group decide which quality was most important? Was there much disagreement?

- What were some of the other choices in your group?

- Which qualities are especially difficult to find in a friend?

- What desirable qualities do you bring to a friendship?

- What qualities would you like to develop in the future?

\section{Limits of Friendships (40 minutes)}

1. Inform the group that this part of the session will explore the limits of friendships. Make it clear that after we have chosen and developed friendships we need to consider how far we are willing to go to keep a friend.

2. Explain that there are brief scenarios in the container. Each is an imaginary situation where someone upsets or concerns a close friend. Each girl is to draw a slip of paper from the container, read aloud the scenario and then the group can discuss their responses. Inform the group that they must imagine that the "imaginary friend" and themselves are very close friends.

3. Facilitate a discussion by asking the following questions.

- Have you thought much about the limits of your friendships? What are two things that you would not do with or for your friends, no matter what?

- Are there things that you would rather not do but would do if a close friend asked? Why?

- Would you do things for certain friends, but not for others? How do you decide?

\section{TAKING IT HOME}

Tell the girls to discuss with their friends what they value in a friend and propose some of the scenarios from the activities in this session. See how they would respond to different scenarios.

Have the girls write in their program journal about a time when a friend asked them to do something difficult and how they responded. If they could do it over again, what would they do differently? What would they do the same way? 


\begin{tabular}{|c|}
\hline \\
If my friend forgot her lunch, I would... \\
\hline If my friend needed to borrow Ghc2.00, I would... \\
\hline If my friend talked about running away from home, I would... \\
\hline If my friend had smashed a window at school and I was asked about it, I would... \\
\hline If my friend had not done a homework assignment and wanted to copy mine, I \\
would... \\
\hline If my friend wanted me to help her steal from a local shop, I would... \\
\hline If my friend told me to stop doing homework because it looked stupid to care about \\
schoolwork, I would..... \\
\hline If my friend asked me to watch a pornographic movie, I would... \\
\hline If my friend told me to stop having sex because of the risks, I would... \\
\hline
\end{tabular}

(Facilitators are encouraged to think of additional examples) 


\section{Session 8: Self Esteem}

\section{Session Objectives:}

By the end of this session, girls will be able to:

- Define self-esteem

- List qualities they like about themselves

- Change negative talk into positive talk

- Explain ways to improve their own self-esteem

\section{Materials Needed:}

- Chalkboard, chalk

- Program journal for each girl

- "Your Identity: Many Parts Make You Strong" handout (p. 39) for Choosing Self activity

- Index cards for each girl

\section{Session Outline:}

- Definition of Self-esteem (30 minutes)

- Choosing Self (30 minutes)

- Promoting Self-esteem (30 minutes)

Total Time: 90 minutes

\section{TAKING IT HOME RECAP}

Ask for a few girls to share about their conversations with their friends. Were they surprised by any of their friends' responses to the scenarios?

Have a few volunteers share about challenges they have had with friends. Ask the group to offer ideas on ways to respond.

\section{INSTRUCTIONS}

\section{Definition of Self-Esteem (30 minutes)}

1. Ask girls to stand up and form two circles, one inside the other, with about half of the girls in an outside circle and the other half in a smaller circle inside the larger circle. Ask the girls in the smaller circle to close their eyes, put their arms around each other, and lower their heads. Ask the girl in the big circle to walk around those in the smaller circle and while they are going around in circles, read the following instructions: 
Give a pat on the back to someone who makes his or her own decisions and sticks to them.

Touch the head of someone who is friendly and understanding.

Give a pat on the arm to someone who works well with others.

Touch the shoulder of someone who is recognized and respected in his or her community.

Touch the shoulder of someone who makes us feel confident.

2. After a few minutes, change places and the members of the big circle switch to be the small circle and vice versa. Continue the activity until you can assure that everyone has been touched in some way by someone else. At the end, ask how they felt when the other classmates touched them? How did you feel when someone patted you on the back? (Happy, good, proud, confident).

3. Write on the board the girls' words, building definitions and ideas with them about self-esteem.

Review the information with them by saying:

In this activity, our friends identified our strengths. We should recognize that we have strengths and values that we should be proud of. It is also good to recognize that we have some weaknesses that we can improve upon.

Explain that knowing ourselves and valuing ourselves is called self-esteem. Self-esteem can influence our actions towards each other.

4. Ask girls to define the word self-esteem. Write their responses on the board. Make sure their definition includes the following:

Self-esteem: Describes how people feel about themselves. How people feel about themselves influences their actions towards others and what they accomplish in life.

5. Ask girls to discuss why self-esteem is important and how we learn self-esteem. Explain that selfesteem is important because how people feel about themselves influences what they accomplish in life. If people believe in themselves and their ability, then they are able to work hard, reach set goals and accomplish what they set out to do. Ask girls to brainstorm what feeling good or having high self-esteem about ourselves helps us to do. Some of the responses should include:

Accept new challenges and try new activities

Be more comfortable with others, and develop closer and healthier relationships

Believe we can succeed

Gain self confidence

Be the person we want to be

Be assertive and refuse to be pushed into what we don't believe in

\section{RIGHT Choosing Self (30 minutes)}

1. Begin by asking the girls for examples of things that people can say to themselves to make them feel good.

2. Tell the girls that sometimes the things we say to ourselves can affect our confidence and self-esteem. Explain that in this activity, they will discuss "self-talk." 
3. Ask the girls to think about things people say to themselves that make them feel bad about themselves (for example, "I'm not smart enough"). Ask the girls to write an example on a card. Collect the cards from each girl and shuffle them together.

4. Divide the girls into teams of 6-8.

5. Ask each team to form a tight, close circle and sit down. Place the same number of cards as there are players in a pile in the centre of the circle.

6. Give 1 girl on each team a talking stick.

7. Explain and demonstrate that:

- The girl holding the talking stick will choose one card from the pile and read the card out loud. The group must provide suggestions to change what is written on the card into a positive statement (for example, "I am a valuable person" instead of "I am no good").

- Only those girls holding the talking stick are allowed to speak. A girl who wishes to speak must request the talking stick before speaking.

- The group will have 3 minutes to discuss each card. After 3 minutes the girl holding the talking stick will choose and read out loud the next card in the pile.

8. Continue until everyone has had a chance to respond to a card.

9. Give each girl a copy of "Your Identity: Many Parts Make You Strong." Ask them to check each box that describes them.

Watch for:

- Does each girl provide an example of negative self-talk?

- Do the girls in each group work together to change the negative self-talk into positive self-talk?

- Is each girl requesting and holding the talking stick when they wish to speak?

10. Facilitate a discussion using the following questions:

- Was it difficult to change the statements into something positive?

- How did it feel to change the negative comments on a card into positive comments?

- Why is negative self-talk dangerous? (Answer: If we say negative things about ourselves, we may begin to believe them and behave as if the beliefs are true. Negative self-talk can cause stress, depression, feelings of powerlessness, etc.)

- What can we do to stop negative self-talk?

- What can we do to remind ourselves of all the things that make us strong? 


\section{Promoting Self-Esteem (30 minutes)}

1. Ask girls to fix a large piece of paper to each other's backs. Have everyone walk around the room looking at people and then write on the sheets on their back any positive thing or feeling they have about them. There are two rules: it must be positive and it must be genuine.

2. Have each girl read out three statements that have been written about them, beginning the sentence with "I am..."

3. Discuss how it can be difficult to accept praise. Ask each girl to add one positive characteristic or strength about herself to the list. Discuss. Was it easy or difficult to recognize our own strengths?

4. Facilitate a discussion with the following questions:

How did this activity make you feel?

Were you afraid people would not have anything good to say about you?

If you can see anyone in the room who you would not give one positive quality, what does that say about you?

Are we positive enough in the way we look at others?

How would it feel not to get praise?

What are some things we can do to help increase other people's self-esteem?

What are some things we can do to increase our own self-esteem?

\section{TAKING IT HOME}

Before the next session, write in your program journal about something positive that happened to you that increased your self-esteem. It could be receiving a compliment, feeling proud of how you did on something, or something different. 


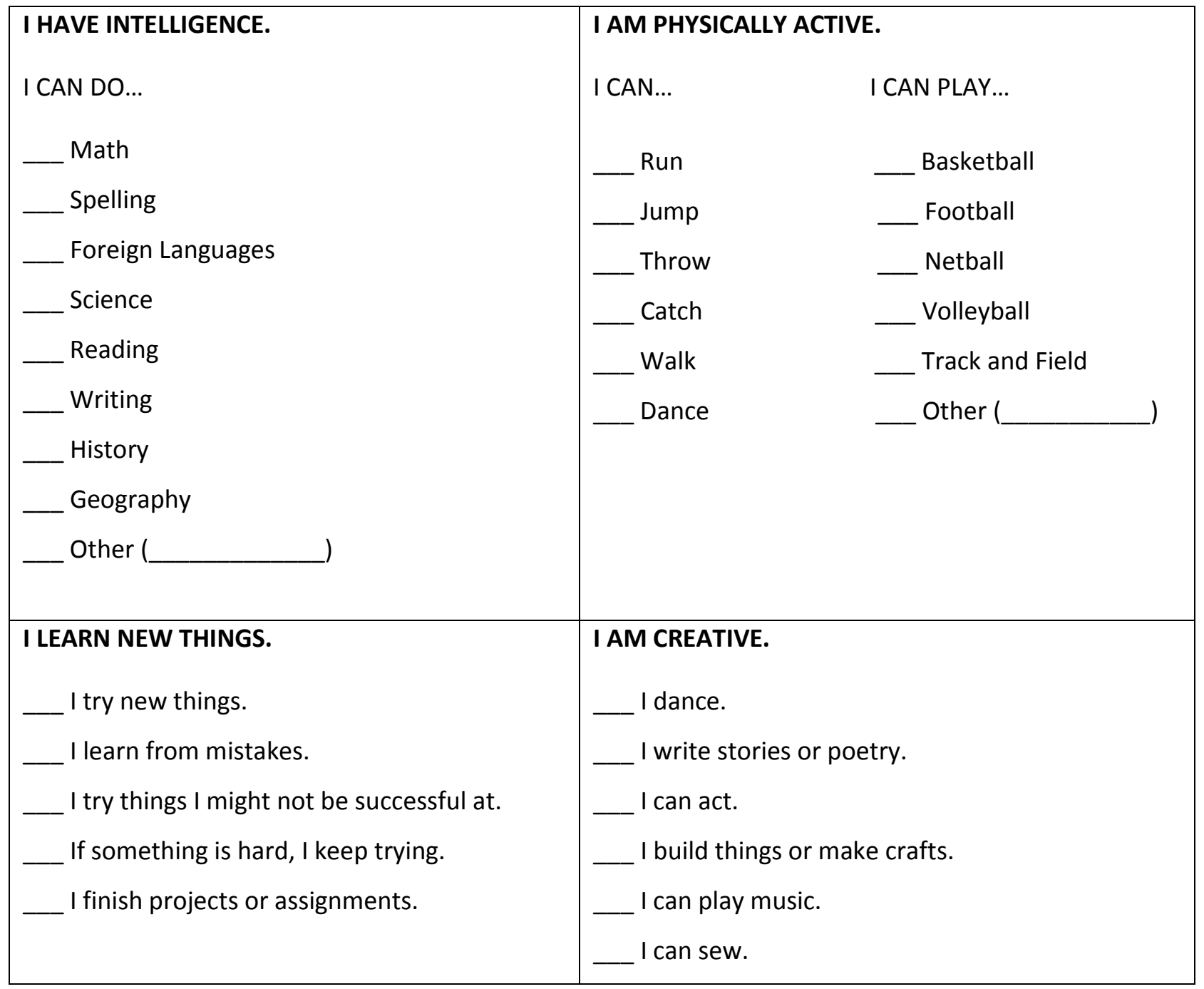


Session 9: Confidence

Session Objectives:

By the end of this session, girls will be able to:

- Define confidence

- Understand why confidence is important

- List ways to increase confidence

- Feel more comfortable speaking in front of a group

Materials Needed:

- Armbands or pieces of cloth for Confidence Tail Tag activity (1 per girl, plus extras to offer as rewards)

- $\quad$ Ball: 1 per group (6-10 girls per group)

- Chalk or makers for marking a grid on the ground

- A variety of writing pieces for girls to choose from for the Making Speeches activity

Session Outline:

- Confidence Tail Tag (20 minutes)

- Confidence Court (20 minutes)

- Making Speeches (50 minutes)

Total Time: 90 minutes

BEFORE THE SESSION: Prepare copies of "speeches" that the girls will read in front of the group. To make this activity more fun, select pieces that would not normally be delivered passionately to an audience, such as the instructions from the packaging of a household cleaner or a paragraph from a textbook. The pieces should be short enough to read aloud in 1-3 minutes.

\section{TAKING IT HOME RECAP}

Ask a few girls to share what happened to them that increased their self-esteem. How did it feel to write about it? Encourage the girls to continue taking note of the positive events that happen in their lives, both big and small.

\section{INSTRUCTIONS}

\section{RIGHT Confidence Tail Tag (20 minutes)}

1. Begin with a discussion using the following questions:

- What does it mean to have self-confidence? 
- What are some reasons people feel self-confident?

- What are some reasons people have low self-confidence?

2. Mark the boundaries for a large play area.

3. Reserve a space at one end of the play area for Confidence Building.

4. Give each girl an armband or piece of cloth and ask them to tuck the cloth into their back pocket, leaving most of the cloth hanging out.

5. Tell the girls that this is their "confidence tail."

6. Explain and demonstrate that:

- The object of the game is to try to take as many "confidence tails" as possible from other players.

- The girls must try to protect their own "confidence tail" from being taken. The girls are not allowed to hold onto their tails with their hands or hit at other girls' hands as their tails are being reached for.

- Once a girl's "confidence tail" has been taken, she must go to the Confidence Building space where you will ask her to perform using a special talent. For example, girls may choose to sing a song, perform a dance or demonstrate physical strength.

- You may have to suggest a simple task if a girl is hesitant to perform.

7. When the girl has completed the confidence-building activity, reward her with a new tail and send her back onto the playing field to continue play.

8. The game ends at your discretion or when you run out of additional tails.

Watch for:

- Are the players being respectful of each other's bodies when taking tails?

- Are the players with tails staying inside the boundaries?

9. Facilitate a discussion using the following questions:

- How did it feel to have your "confidence tail" taken away?

- What did you do to get out of the Confidence Building space?

- In real life, how do you build the confidence to try something new? (Possible answers include: Imagine a scenario and practise a response. Talk to your friends about what you would do.)

- What can you do to help others feel more confident in life?

\section{RIGHT Confidence Court (20 minutes)}

1. Begin with a discussion using the following questions: 
- What is an example of an ability? A skill? An interest? An experience?

- How do you think that abilities, skills, interests and experiences relate to self-confidence?

2. Mark a grid with 4 squares on the ground using chalk or markers. This is the Confidence Court.

3. Label the squares, Confidence Level 1, Confidence Level 2, Confidence Level 3, and Confidence Level 4.

4. Explain that each girl has a number of abilities, skills, interests, and experiences. Tell the girls that abilities, skills, interests and experiences can help build confidence if they are recognized and nurtured.

5. Ask 4 volunteers to choose a square on the Confidence Court. The remaining players should form a single-file line outside the Confidence Court, at the corner of the Confidence Level 1 square.

6. Explain and demonstrate that:

- The object of the game is to be the girl who stays in the Confidence Level 4 square for the longest time.

- All the other girls will try to move up a level and challenge for the Confidence Level 4 square.

- Tell the girls that there are four categories in the court: Abilities, Skills, Interests, and Experiences. Provide the girls with examples of abilities (read), skills (play basketball), interests (listening to music) and experiences (going to a big football match).

- The girl in the Confidence Level 4 square chooses a category before play begins.

- If this girl called out "Category: Skills," the girl then names one skill and bounces the ball into another girl's square. The skill can be a skill the girl has or someone else has.

- When the ball enters a square, the girl in that square bounces the ball and calls out an example in the appropriate category (for example, in the Skills category, "play football").

- Girls must pass the ball by bouncing it on the ground without catching it.

- This continues until a girl is eliminated because she passes the ball out of bounds, doesn't give an example in the category, or calls out an example that has already been mentioned.

7. When a girl is eliminated, she must leave the Confidence Court and tell the mentor (facilitator) one personal skill or ability she has before rejoining the line.

8. When a Confidence Square has been left by a girl, the other girls on the court move up a level. (If there is a girl in the Confidence Level 4 square, that girl stays there.)

9. A new girl from the line always joins the game at Confidence Level 1.

10. At the beginning of every new round the person in the Confidence Level 4 square selects the category.

Watch for:

- $\quad$ Are different players getting into the Confidence Level 4 square? 
- Are different categories being called out?

11. Facilitate a discussion using the following questions:

- How did it feel to announce your abilities, skills, interests, and experiences out loud?

- What is something you are more confident doing now than before? What helped you to feel more confident?

\section{Making Speeches (50 minutes)}

1. Have each girl choose one piece to present to the group, and give them a few minutes to read it over and practice. It's okay to have multiple girls choose the same piece.

2. Ask the girls to come up one at a time and present their pieces. Challenge them to read their "speech" with as much personal style and passion as they can.

3. After each girl has presented, facilitate a discussion by asking the following questions.

- What made the performances interesting for the audience?

- How did it feel to stand up and read in front of the group?

- What are some other things we have to do in life that require a lot of confidence?

- What are some ways that we can build confidence?

\section{TAKING IT HOME}

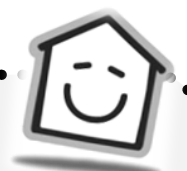

Have the girls write in their program journals about a time when they had to use confidence to do something. What made it challenging? How did they feel beforehand? How did they feel afterwards? 


\section{Session 10: Being Assertive}

\section{Session Objectives:}

By the end of this session, girls will be able to:

- Distinguish between assertiveness, aggression, and passiveness

- Assess their own level of assertiveness

- Demonstrate effective assertiveness skills

\section{Materials Needed:}

- Poster with the Six Golden Rules of Assertiveness listed

CRichard Lord

- Program journal for each girl

- Slips of paper with terms and situations for Assertiveness and Aggression - enough copies for each small group (p. 51)

- Flipchart and markers

- "Situations for Practicing Assertiveness" Sheet - enough copies for each small group (p. 52)

\section{Session Outline:}

- Assertiveness and Aggression (40 minutes)

- Assertiveness Assessment (10 minutes)

- Practising Assertiveness (40 minutes)

Total Time: 90 minutes

BEFORE THE SESSION: List the Six Golden Rules of Assertiveness (p.50) on a poster to hang on the wall.

\section{TAKING IT HOME RECAP}

Ask a few girls to share what they wrote about using confidence. What made it challenging? How did they feel beforehand? How did they feel afterwards?

\section{BACKGROUND NOTES}

Assertiveness is an essential skill for getting along with others. Being assertive means standing up for yourself. To be assertive is to be straightforward and honest with yourself and with other people about what you need and want. Being assertive can help you protect yourself from dangerous situations and can help you deal with peer pressure to do things that you are uncomfortable doing.

People who are not assertive are often very passive and submissive. Even if they are being treated poorly, they do not stand up for themselves. People who are not assertive often lack the confidence and 
self esteem to stand up for their own needs and to protect their feelings or body from being hurt. In many cultures assertiveness is not valued in girls, making it hard for them to stand up for themselves.

Assertiveness is very different from being aggressive. People who are aggressive are rude and unkind. They do not care about other people's feelings. Being too aggressive is not very good for your emotional health because, deep down, you will feel bad about being unkind.

\section{INSTRUCTIONS}

\section{Assertiveness and Aggression (40 minutes)}

1. Ask the girls to discuss what they understand by the terms assertiveness and aggression. Make sure their definitions are similar to the ones below. Ask them to list differences between being assertive and aggressive:

Assertiveness: expressing thoughts, feelings and beliefs in a direct, honest and appropriate way. Aggression: a feeling of hostility that may lead to attacks or an unprovoked violent action.

2. Make sure girls understand the two terms by explaining:

Being assertive is standing up for what you believe in and what you want. Young people are often tempted to give in to someone else's desires, whether because of peer pressure or something idealized in the media. However, if we say what we want or feel and explain why we have chosen a certain decision or action, then we can do what we really want without hurting another person. Assertiveness is part of effective communication. When you are assertive you can say no without feeling guilty, can ask for help when it is needed, avoid arguing, disagree without becoming angry, and feel better about yourself.

Being aggressive involves putting other people down, blaming, or criticizing them.

3. Go over the Six Golden Rules of Assertiveness, using the additional information to elaborate on the each rule. Clarify any questions. Then facilitate a brief discussion using the following questions.

- Which rules are the most important for being assertive?

- Which rules are the easiest to follow?

- Which ones are the most difficult to follow?

4. Explain that assertively expressing your feelings involves "I" statements. These statements begin with a person expressing how he/she honestly feels, then states when or under what circumstances he/she feels this way and why, and then what he/she needs or would like to change. Write the following statement on the board.

I feel when you because and I would like/want

Share one or two 'I" messages using the format you wrote on the board. Some examples include: 
- I feel upset and angry when you call me stupid and I would like you to stop calling me names.

- I feel uncomfortable when you try to pressure me to use drugs (or smoke) because I have made the personal choice not to use drugs (or smoke) and I would like you to stop doing that.

5. Divide the girls into groups of 3-5, and ask each group to think of a few more examples of "I" statements. Allow about 5 minutes for the groups to think of their statements. Ask each group to share one or two of their statements.

6. Read the following scenario aloud to the girls:

Naa was so glad that the school day was over. She had had two exams that day and was looking forward to meeting her friends at the nearby kiosk for some snacks. She had just enough money to buy a soda and some chips. She bought them and went to sit with her friends. Just as she was about to start eating, John came up behind her and took one. "Good chips," he said, "Can I have another?" Before Naa could answer, her friend Afi said, "Can I have one too? I'm still so hungry" and took some. Then another friend said, "If you sit here you have to share your food with us," and he proceeded to take more of Naa's chips.

7. Give each small group the slips of paper with Naa's reactions and the matching terms that describe each reaction. Make sure each group gets 8 slips -4 different reactions and the matching terms.

8. Have the groups to match each reaction with the appropriate term. Bring everyone back together and ask girls to share their answers.

9. Use the following to explain the correct answers:

Passive: Reaction 1. Your friends told you what they wanted but you did not tell them what you wanted. Passive people may believe that others are always telling them what to do and they play the role of victim. They allow others to violate their rights. A passive response is not always in your best interest. However, there are some situations when a passive response is the most appropriate. Ask the girls to give some examples.

Directly Aggressive: Reaction 2. You say what you want in a threatening manner that offends others. This response is generally not in your best interest and often leads to conflict.

Indirectly Aggressive: Reaction 3. You pretend everything is fine, but then act with hostility towards your friends. Because you did not express your feelings, your friends are left to guess what they have done wrong. It leaves your friends and yourself frustrated.

Assertive: Reaction 4. You knew what you wanted and expressed it in a straightforward manner. You were sensitive to the feelings of your friends, which made you feel good about yourself, and your friends know where they stand with you. It is a solution that leaves everyone satisfied.

9. Ask girls to imagine that aggressiveness, assertiveness, and passiveness are like a seesaw. The aggressive person is at the top, looking down on everyone else. The assertive person is perfectly 
balanced in the middle and quite comfortable with him/herself and others. The passive person is at the bottom, looking down at the ground and feeling bad.

10. Write each of these words at the top of three different posters: AGGRESSIVENESS, ASSERTIVENESS, PASSIVENESS. Ask the girls to think of different words to describe a person who is passive, a person who is assertive, and a person who is aggressive. Have them walk around and write down their suggestions on the appropriate posters. Use the following as a guide:

- Aggressiveness: Expressing your feelings or desires in a way that threatens or punishes others; insisting on your rights while denying their rights. Dominating - shouting, demanding, not listening to others. Looking down on people. Saying others are wrong. Pointing fingers at others, threatening, fighting.

- Assertiveness: Telling someone exactly what you want in a way that does not seem rude or threatening to them standing up for your rights without endangering the rights of others. Balanced knowing what you need to see - say "I feel" not "I think" - be specific - use "I" statements - look the person in the eye - stand your ground - do not whine or be sarcastic.

- Passiveness: Giving in to the will of others - hoping to get what you want without actually having to say it - leaving it to others to guess or letting them decide for you. Being submissive, talking quietly, nervous, giggling, looking down or away, sagging shoulders, avoiding disagreement, and hiding the face with hands.

\section{Assertiveness Assessment (10 minutes)}

1. Explain that this exercise is designed to help them discover how assertive they already are. Ask each girl to take out a sheet of paper. For each of the following statements, ask them to write an $\mathrm{M}$ for most of the time, $\mathrm{S}$ for some of the time, and $\mathrm{N}$ for almost never.

I can express my feelings honestly.

When I say how I feel, it is not to hurt someone else.

I express my view on important things, even if others disagree.

I offer solutions to problems instead of just complaining.

I respect others' rights while standing up for my own.

I ask my friends for a favour when I need one.

I take responsibility for my own feelings instead of blaming others.

If I disagree with someone, I don't use verbal or physical abuse.

I can admit when I'm angry.

I can say "no" without guilt or an apology.

I do not do risky things with my friends.

I ask for help when I am hurt or confused.

2. Ask girls to count how many times they each scored M. They can compare their scores as follows:

$0-4$ : Need to work hard at being assertive.

5 - 9: Somewhat assertive, but could improve.

$10-12$ : Good and keep practicing. 


\section{Practising Assertiveness (40 minutes)}

1. Divide the girls into groups of six, and give each group one of the scenarios on the "Situations for Practising Assertiveness Skills" sheet. Explain that the girls are going to do a role-play of their scenario, and in each group, two people act out the situation in a passive way, two in an aggressive way, and two in an assertive way.

2. While the groups are practicing, walk around to all of the groups to make sure the groups understand the different types of behaviour, and to offer assistance to any groups that are having difficulty. Have two or three groups perform all three of their role-plays.

3. After each role-play discuss the following questions:

- Was this a passive, assertive, or aggressive response to the situation?

- Was the reaction effective? Why or why not?

- What were the values behind each character's behaviour?

For the people in the role-play:

- How did you feel doing this role-play?

- Would you adopt this character in real life? Why or why not?

4. Facilitate a discussion with the girls using the following questions:

- What can we learn about real life situations from the role-play?

- How can assertiveness skills help you handle different situations in your life?

- How can it especially help deal with anger constructively?

- Why is it sometimes difficult to be assertive?

- How can being assertive help in a relationship? In a family?

Explain that our goal might be to develop assertive behaviours but most of us find it very difficult and we usually revert to submissive and aggressive behaviours. Developing successful assertive behaviour takes time, practice, and patience

\section{TAKING IT HOME}

Ask the girls to write down one or two assertiveness goals to work on during the next week. These could be behaviors from the Assertiveness Assessment, or the girls can come up with ideas for their own personal goals.

Ask the girls to observe their behavior over the next week and write down a situation where they acted passively, aggressively, or assertively, and how their reaction made them feel. 


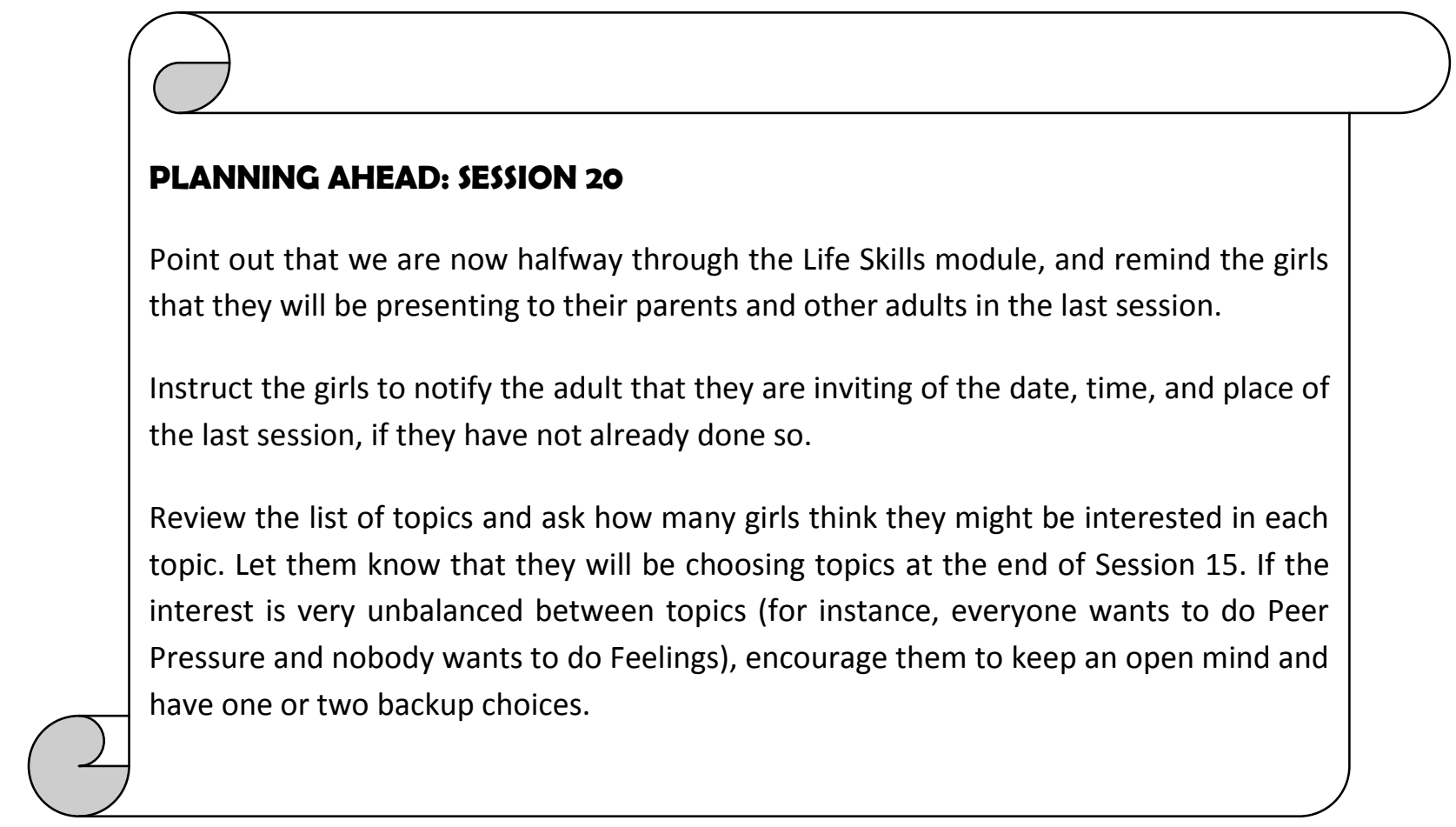




\section{SIX GOLDEN RULES OF ASSERTIVENESS}

\section{Decide what you feel or want and say it.}

2. Maintain eye contact.

3. Do not make excuses.

4. Do not seek approval from others.

5. Do not get confused by the other person's argument.

6. Remember you have a right to change your mind.

\section{ADDITIONAL INFORMATION:}

\section{Decide what you feel or want and say it.}

Don't be afraid to be honest about your feelings. Being confident about your own feelings will encourage others to respect them as well. Someone who truly loves you will not want to do things that make you feel unhappy.

\section{Maintain eye contact.}

Eye contact (looking someone in the eye) is an important part of being assertive. It tells the other person that you are serious about what you are saying and that you are paying close attention to whether or not they are listening to you. Eye contact is not encouraged in many cultures, and in some places it may be considered rude. One way to deal with this is to follow traditional customs that show respect, while still maintaining eye contact when you need to be assertive.

\section{Do not make excuses.}

Your feelings are the best reasons. For example, if you do not feel ready for sex, but your girlfriend or boyfriend is pressuring you, avoid using other people as excuses. Say what you really feel.

\section{Do not seek approval from others.}

If you do not want to do something, say so clearly and do not ask if it is okay. Show other people that you know your own mind and are not looking for their approval.

\section{Do not get confused by the other person's argument.}

Keep repeating what you want or do not want. Stand your ground and do not give in.

\section{Remember you have a right to change your mind.}

Perhaps you and your boyfriend talked about sex a few days ago and you told him that you would have sex with him. But you have had another couple of days to think it over, and now you feel sure that the time is not right - that you are not ready and that the relationship is not ready. He says: "But you agreed that we could have sex." Tell him: "I've changed my mind, I've decided I don't feel ready." If he truly loves you, he will respect your right to change your mind, and he will wait until you feel ready. 
Reaction 1: Apologize to your friends for not sharing your chips and let them eat all of them.

Reaction 2: Grab the chips and say you are going to eat all of them yourself.

Reaction 3: Silently allow the friends to eat the chips, and then ignore them so they will know you are angry with them.

Reaction 4: Explain to your friends that you have been looking forward to having the chips all week and that you'd share some with them as long as they leave enough for you.

\section{PASSIVE}

\section{DIRECTLY AGGRESSIVE}

\section{INDIRECTLY AGGRESSIVE}


1. A group of girls are teasing your friend because of her appearance. They look to you to join in. They say 'Isn't this girl a real idiot?'

You say:

- Aggressive response ...

- Submissive response ...

- Assertive response...

2. You are in a shop with a friend. You see her steal some sunglasses and put them in her pocket. Your friend says casually, "Why don't you take a pair as well, are you scared?

You say:

- Aggressive response ...

- Submissive response ...

- Assertive response...

3. You bought a pair of expensive shoes at a road side shop two days ago and they have already started to come apart at the sides. On taking it back to the shop you ask the sales person for a refund or replacing these with a different pair, commenting that you think the shoes were poorly made. The sales person says “You didn't wear them property. And anyway, it's not our policy to give refunds or replace. I told you on the day that you purchased it that we do not refund or replace the items once sold".

You say:

- Aggressive response ...

- Submissive response ...

- Assertive response...

4. You are spending an evening with your friends. Everyone is being offered cigarettes, drugs and alcohol and some people agree to take them. You choose not to take any of them. Some start to call you 'a coward'.

You say:

- Aggressive response ...

- Submissive response ...

- Assertive response...

5. You lent some money to a friend about two months ago, and have phoned twice to ask for it back. You run into her in the street, and ask for the money to be returned in 24 hours. She says 'Oh, don't worry. I'll give it back sometime I guess.'

You say:

- $\quad$ Aggressive response ...

- Submissive response ...

- Assertive response... 
Session 11: Decision Making

Session Objectives:

By the end of this session, girls will be able to:

- List the three steps in making a decision

- Apply the three C's for decision making to different situations

\section{Materials Needed:}

- Poster listing the Three C's for Decision Making

- Balls: 2

- Chalk or markers for marking a grid on the ground

- Flipchart or chalkboard

- Program journal for each girl

\section{Session Outline:}

- Spot the Gap (20 minutes)

- Three C's for Decision Making (70 minutes)

Total Time: 90 minutes

BEFORE THE SESSION: Write out the Three C's for Decision Making on a poster to hang on the wall:

1. Describe the CHALLENGE (or decision) you are facing

2. List three CHOICES you have

3. Consider the positive and negative CONSEQUENCES of each choice

\section{TAKING IT HOME RECAP}

Have a few volunteers share their assertiveness goals and what they've been doing to work towards those goals.

Ask a few of the girls to share the situation that they wrote down, and how it made them feel.

Remind the girls that it can be hard to act assertively, but if they keep practicing, it will become easier.

\section{BACKGROUND NOTES}

A decision is a choice that we make between two or more possible courses of action. We all make decisions every day. We will need to make more and more decisions as we go through life and some of these decisions will affect us the rest of our lives. 
One of the most important parts of decision making is looking ahead to see what might happen if you do something. This is called predicting outcomes or understanding consequences. The better you are at predicting outcomes, the better you will be at making decisions that result in the outcomes or consequences you want. Understanding the possible consequences of our decisions help us to cope with the choices we have to make about our lives.

Key steps for good decision-making include:

Describe the problem, situation, or issue that is calling for a decision.

Get more information if you have questions about the situation.

Think about the possible consequences or outcomes of each course of action.

Think about your personal and family values, and which courses of action are consistent with these values.

Think about the ways in which your decision may affect other people.

Choose the decision that seems most appropriate based on your knowledge, values, morals, religious upbringing, and present and future goals.

Re-think the decision and how you feel about it - whether you feel that you carefully considered all the alternatives and feel comfortable with the choice you made.

\section{INSTRUCTIONS}

\section{RIGHT Spot the Gap (20 minutes)}

1. Begin with a discussion using the following question:

- When you play a sport or game, how do you decide when to try to score or pass the ball? What do you look for? What do you listen for?

2. Explain that in this game, the girls will practise making good decisions.

3. Mark the lines for a grid, approximately $10 \times 10$ metres.

4. Divide the girls into four equal-sized teams, Teams A, B, C, and D.

5. Ask each team to line up single file on each side of the grid. Two teams should be facing each other.

6. Give a ball to the first girl in line on Teams $A$ and $C$.

7. Explain and demonstrate that:

- When you say "Go," the girls with the balls will pass the balls with their feet, across the grid to the first girl in line on the opposite team.

- When girls make a pass they must follow their ball and run across the grid to the end of the opposite team's line. 
- Play continues as quickly as possible, with girls passing to the opposite girl, waiting for a gap, then following their pass and joining the end of line on the opposite side of the grid.

- There must be two balls in play at once.

- If two girls collide with each other, both girls are out of the game.

- If two balls collide, then both girls who caused the collision are out of the game.

8. The game ends at your discretion or when one side of the grid is down to one girl.

Watch for:

- Are the girls waiting for a gap before passing and running to the opposite side of the grid?

- Are the girls joining the end of the opposite team's line?

9. Facilitate a discussion using the following questions:

- What did you do to make sure your ball made it through?

- If you were eliminated from the game, how did it happen?

- In real life, what kinds of decisions require time to make?

- Who can you go to for help when making decisions about your life?

- What can a person do if they've made a poor choice? (Possible answers include: Try again. Get support from friends to help the person make better choices).

\section{Three C's for Decision-Making (70 minutes)}

1. Explain that making decisions and knowing the consequences are important skills young people need. Explain that there are three steps for active decision making. Sometimes this is done very carefully, other times very quickly. Some decisions can take a few days, others can take years, while others are made instantly. Present the Three C's for making decisions.

2. Ask girls to take out a piece of paper and write down a serious decision that they or their friends are currently facing. The decision can be about anything - school, a job, a family situation, or a friend. Instruct them to choose a decision where the consequences really matter, instead of something that will not make much difference. Assure them that what they write will remain confidential.

3. Collect the papers in a basket or hat. Read them quickly and choose five or six that are tough decisions, and write them on the board. If what is written can be used to identify the writer, change it accordingly to maintain confidentiality.

4. Explain to the group that these are the kind of challenges many young people face, especially as they become older and more independent. Young people must make decisions and learn to live with the consequences.

5. Ask girls to choose one of the challenges listed on the board. Ask the group to brainstorm several choices or options that a person making this decision has and write them on the board. List those beside 
the word 'choices' on the board and add any others that you can think of. Be sure there are at least three choices.

6. Remind girls that there are consequences to their decisions. Ask them to think of possible negative and positive consequences for each choice. Add any obvious consequences the group may leave out, especially negative ones. Point out that the number of choices should not determine the best choice. You should note the intensity or weight of each choice.

7. Ask girls to look at the choices and consequences and make a choice together. Try for consensus or take a vote to determine the outcome. Clarify that decision-making is usually done alone, but people may seek other people's opinions before making a decision.

8. Divide girls into groups of four. Assign each group one of the other challenges from the list on the board. Have them follow the Three C's and make a decision. Once each group has made a decision, allow a representative from each group to share their decision and process with the whole group.

9. Facilitate a discussion with the following questions:

Do certain decisions warn you right away to choose something else? If so, what are they? (Possible answers: A risk to health or to your own or someone else's life, a risk of going to jail, a risk of losing your integrity)

What negative consequences relate to a person's feelings or values? (Answers include: guilt about choosing against your values; feeling bad for doing something your parents, religion, traditions or culture, or friends would disapprove of; or feeling used or exploited)

When facing a tough challenge and are unsure of the decision to make, who could you ask for help? (Possible answer: friend who has gone through a similar decision, teacher, guide leader, school counsellor, religious leader, parent or other trusted adult)

How can you explore all the possible consequences of a particular choice?

Are you facing a personal decision now? Can you use this decision making process to help you?

\section{TAKING IT HOME}

Ask the girls to use the Three C's for decisions that they make during the next week. Have them write down one decision and how they worked through the Challenge, Choices, and Consequences to make their decision. 


\section{Session 12: Peer Pressure}

Session Objectives:

By the end of this session, girls will be able to:

- Understand different situations in which peer pressure occurs

- Recognize when peer pressure is positive and when it is negative

- Understand how peer pressure can influence decision-making

\section{Materials Needed:}

- Long bar, stick, or rope

- Paper and pens or pencils for each small group

\section{Session Outline:}

- Limbo Pressure (20 minutes)

- Positive and Negative Peer Pressure (70 minutes)

Total Time: 90 minutes

\section{TAKING IT HOME RECAP}

Ask for a few volunteers to share the decision they wrote down and how they worked through the Challenge, Choices, and Consequences to make their decision. Did using the three $C^{\prime}$ s help them in deciding what to do?

Point out that it is important to analyze the Three C's for decisions that could have a major impact on a person's health or future.

\section{BACKGROUND NOTES}

Even though young people often report that they learn more from friends when they reach adolescence, studies have found that these same adolescents would prefer to learn about a variety of important topics from their parents or other caring adults. Peer influence does increase during the teen years, but the influence of caring adults can remain strong if you've established a strong relationship during the earlier years. Most peer pressure for young people is just as subtle as it is for most adults.

This is why practising resisting peer pressure is important. Finding creative ways to refuse alcohol, tobacco, drugs, and sex requires humour and lots of practice. Each young person can help develop his or her own favourite set of "turn down" comments, but it's your job to help them practice these so that they are not thrown off balance if the offer is more subtle or more direct than what was anticipated. A 
lot of this will depend on the age and attitude of the child, and the most important thing is to make sure the child is comfortable with what he or she wants to say. Your job is to coach them to use language and phrases that they come up with themselves to resist peers pressuring them to use drugs, have sex, or drink alcohol.

The younger the child, the more practice he or she will need. This cannot be a one-time session. You might find, for instance, that a 10-year-old has no trouble whatsoever saying no to a suggestion that he try a beer at a neighbour's house. However, 3 years later when the 17-year-old next door asks him if he wants a beer, you hear him hesitate because he is not as sure of himself and his convictions at 13 as he was at the age of 10 .

\section{RIGHT Limbo Pressure (20 minutes)}

1. Begin with a discussion using the following questions:

- What are some examples of pressure you place on yourself?

- What are some examples of things that friends or peers often pressure each other to do?

2. Ensure the play area is clean and free of obstructions.

3. Ask two girls to hold the bar, stick, or rope level with the ground at shoulder height.

4. Explain and demonstrate that:

- One by one, the girls will go under the bar. They must stay on their feet, and the girls' heads must be last to go under the bar. This is called limbo.

- All girls will go under the bar once. When all girls have gone under the bar, lower the bar.

- If a girl cannot go under the bar, that girl is eliminated. Continue playing until all girls have had a chance to go under.

- Continue to lower the bar for each round.

5. Ask the girls who have been eliminated to clap and encourage the remaining girls to try to limbo under the bar.

6. Lower the bar after each round, until the last girl is eliminated.

Watch for:

- Are all the girls getting a chance to limbo?

7. Facilitate a discussion using the following questions:

- Was it easy to go under the bar the first time?

- As the bar was lowered, how did you feel?

- How did it feel to have people encourage you? What would it have been like if nobody encouraged you? 
- Imagine that the bar is like peer pressure. How does peer pressure affect how we feel?

- Why is it difficult to achieve a goal when peer pressure gets stronger?

\section{Positive and Negative Peer Pressure (70 minutes)}

1. Divide the girls into small groups of four or five, and assign each group a role play about positive or negative peer pressure. Tell the girls that this activity will give them a chance to practice using the Three $\mathrm{C}^{\prime}$ 's model so they will be able to use it to make major decisions and resist peer pressure. Instruct each team to use the Three C's model to write out the challenges, choices, and consequences for their decision on the board. The groups should spend about 5 minutes on this, and another 5-10 minutes to practice their role-plays.

The following are four possible stories that can be given to each of the groups. Each group should be told about its story, but the other groups should not know. As girls prepare the role plays, they should remember to involve everyone in their group and treat each member respectfully. Do not use a real situation that might embarrass someone.

STORY 1 (Negative): A girl named Kukua who just moved to the community is standing by the road. Two other girls who have lived in the community for a long time walk by her. The community girls do not like the strange clothes that Kukua is wearing. They make comments that her clothes are ugly and that she is not one of them. What should Kukua do?

STORY 2 (Positive): A girl named Esi does not have a boyfriend. She wants a boyfriend very much and asks her friend Adowa to help her find one. Adowa tells Esi that they are both lucky to be able to go to school, and they should focus on studying hard so they can do well. Adowa thinks that having boyfriends would distract them from their schoolwork. What should Esi do?

STORY 3 (Positive): Mansa wants to do well in school but she does not understand the teacher's lessons. Mansa is not doing well on the tests that the teacher gives. Many of Mansa's friends tell her how important it is to ask questions when she does not understand an idea in school. They agree that they will also ask more questions to help Mansa feel better about her questions. What should Mansa do?

STORY 4 (Negative): Ama's father gave her money to go to the market and buy eggs for her family. On the way, Ama meets some girls who have new earrings. They tell Ama that their fathers gave them money to buy these earrings. Ama thinks that she should have nice earrings, too, but she knows that her father would get very angry if she did not buy the eggs for her family. What should Ama do?

(Facilitators are encouraged to think of similar examples, or allow the girls to make up their own story.)

2. Call the groups up one at a time for their role plays. 
3. Facilitate a discussion by asking the following questions.

- Which stories showed negative peer pressure and which stories showed positive peer pressure?

- How did the girls feel when a girl faced negative peer pressure?

- How did they feel when a girl faced positive peer pressure?

- Is it difficult to make good decisions? What makes it difficult? (Possible answers are: the influence of alcohol, pressure from peers or a partner or not realizing a decision has to be made.)

- What makes it easier? (Answers include: knowing how to resist pressure, being sure about your values and goals.)

- In reality, how are most decisions made? (They are not made consciously, and events or things just happen).

- In the past, have you made a decision that affected other people? What happened? Have you ever drifted into a decision or let someone lead you into a decision? What were the consequences?

\section{TAKING IT HOME}

Tell the girls to think of ways that pressure from their peers can be helpful to both them and their peers in trying to achieve something. Suggest that they start an activity or accomplish something using positive peer pressure. 


\section{Session 13: Saying "No"}

\section{Session Objectives:}

By the end of this session, girls will be able to:

- List a variety of ways to say "no"

- Demonstrate effective skills to resist peer pressure

Materials Needed:

- Flipchart or chalkboard

- Chalk or tape to mark a line on the ground

\section{Session Outline:}

- No means Stop (20 minutes)

- Refusing What You Don't Want (60 minutes)

Total Time: 80 minutes

TAKING IT HOME RECAP

Ask the girls what they were able to accomplish using positive peer pressure. Did they think of any more ways that positive peer pressure can help them and their friends?

Explain to the girls that today's session will be about Saying "No" in different ways, and that this is a skill that can help them in situations where they feel pressured by their peers or others.

\section{INSTRUCTIONS}

\section{RIGHT No Means Stop (20 minutes)}

1. Begin with a discussion using the following question:

- Why do you think it's difficult for some people to say "no" to things they don't want to do?

2. Mark a start line approximately 10 metres from the mentor (facilitator).

3. Ask the girls to line up behind the start line.

4. Explain and demonstrate that for Round 1:

- The girls must focus on listening. To play well, they have to understand that "No" means "Stop."

- When the mentor (facilitator) says "Go," the girls run towards the mentor. When the mentor says, "No," the girls must freeze. 
- Any girls that are still moving after the mentor says "No" must return to the start line.

- The first girl to reach the mentor is the winner.

5. Ask the girls how they say "no" if they don't want to do something. Explain that people say "No" in many different ways when they are pressured to engage in high-risk activities.

6. Ask the girls for examples of different ways people say "No." (Answers may include: "I'm not ready," "I want to wait," "I want to wait until I'm married," "I don't want to," or "I'm not sure I'm ready.")

7. For Round 2, explain that you will play the game again, but this time you will also include "No" statements (such as "I don't want to"). Explain that you will also mix in other statements such as "I want to play basketball," and "I like listening to music." When they hear these statements, the girls have to run towards you. When they hear you say "I'm not ready" (a "No" statement), the girls must freeze.

8. Each player to reach the mentor earns a point.

9. The game ends at your discretion.

Watch for:

- Are all the girls stopping when they should?

10. Facilitate a discussion using the following questions:

- Was it hard to listen the first time you played the game? The second time?

- In real life, why is it important to listen to others when they say no?

- What can you do if someone keeps pressuring you after you say no? (Answers may include: try talking to a friend, give other ideas of fun things you can do together that are not high risk, consider leaving the relationship if your partner won't listen, etc.)

\section{Refusing What You Don't Want (60 minutes)}

1. Remind girls that there are two ways to get what you want or need:

1) by asking for what you want and

2) refusing what you do not want.

Explain that in this session, girls will practice refusal skills.

2. Ask girls to think about the following scenario:

Baba and Adjo are walking home after school. Baba wants to meet her boyfriend at the market and asks Adjo to go with her. Adjo's mother will be very upset if she is not home right after school. Baba tells Adjo that she can just tell her mother that they had a girls' group meeting. 
Adjo does not want to lie to her mother and she does not think that it is a good idea to go see Baba's boyfriend because he is older and does not seem like a very nice man. Baba promises Adjo that they will not stay too long and also that her boyfriend's friend likes Adjo and wants to talk with her.

3. Ask if anyone can describe what Adjo is probably feeling in this situation. Write the feelings on the board. They should include emotions like "pressured," "confused", "frustrated", "nervous", or "angry." Point out it is also normal to feel angry if a friend puts you on the spot by asking you to do something the friend knows is not in your best interest.

4. Point out that Adjo has rights in this situation, like anyone does when asked to do something. Go over the list of Adjo's rights:

- The right to say how she feels in this situation.

- The right to say no without feeling guilty.

- The right to behave in her own best interest.

- The right to change her mind (even if she had agreed to do what was asked).

5. Ask girls to discuss what advice they would give to Adjo. Then mention that sometimes parents, teachers, employers or other adults in authority make requests of adolescents. The request may not please the adolescent and may not feel like it is in her or his best interest. Ask how an adolescent's rights are similar or different with a parent than a friend. Explain that some adults, such as teachers, parents and family members, do have the right to make requests of young people. Unless the adult is asking for something that is illegal, harmful or seriously disrespectful of the teen, it is often not appropriate for an adolescent to refuse the request. Adolescents do, however, have the right to say how they feel.

6. Ask the group to brainstorm the behaviours Adjo needs to use to be assertive. Write their responses on the board or newsprint and be sure the list includes the following behaviours:

- Say no with her words.

- Say no with her body. Use strong language, make eye contact, stand back from Adjo, who is pressuring her.

- Keep repeating no without giving any excuses or reasons.

- Turn the conversation around and tell Adjo how she feels about being pressured into doing something not in her best interest.

- Offer a compromise. Find a solution that does not require Adjo to do something she does not want to do.

- Leave the situation and refuse to discuss the matter anymore and walk away if necessary.

7. Ask for a volunteer to role-play Adjo, while you play Baba. Tell the rest of the group to coach the volunteer so she can remain assertive in the face of pressure. 
8. Re-read the scenario. Then role-play with the volunteer using lines like the following to pressure her or him:

- "Come on, you're supposed to be my best friend. I really want to see him and his friend really likes you."

- "Your mother won't even know. We will only go for a little while."

- "What's the matter, are you afraid? Irene would come with me if she were here."

Continue for a few minutes, encouraging the audience to coach Adjo.

9. After the role-play, ask girls to identify the behaviours "Adjo" used to be assertive. If there is time, have another volunteer try the role-play.

10. Facilitate a discussion with the following questions:

- When could you use a "coach" when faced with real pressure from a friend or a romantic partner?

- Which is most difficult, speaking up for your wants or refusing what you do not want? Why?

- Think of a recent situation in which you wanted to refuse a request but were not able to. Which refusal skills could you have used?

- Do you have a situation now where someone is pressuring you to do something that is not in your best interest? What could you do to be more assertive in that situation?

\section{TAKING IT HOME}

Tell the girls to develop their own strategies to deal with negative peer pressure and to try them out when they need to. 
Session Objectives:

By the end of this session, girls will be able to:

- Be aware of the importance of problem solving skills

- Be aware of the significance of understanding feelings in problem solving

- Be able to use a problem solving method called "STAR"

- Have a broader understanding of the options for conflict resolution

- Be able to practice the skills of negotiating

\section{Materials Needed:}

- Flip chart, easel, blackboard, markers

- Paper and pens or pencils for small groups

- STAR problem solving model handout for each girl (p. 69)

- "Problem Solving Scenarios" handout - enough copies for each small group (p.70)

- A pre-prepared poster of "Ways of Resolving Conflict"

- A pre-prepared poster "Four Steps of Successful Win/Win Negotiation"

\section{Session Outline:}

- STAR Model for Problem Solving (45 minutes)

- Resolving Conflict (45 minutes)

Total Time: 90 minutes

BEFORE THE SESSION: Prepare two posters: One listing the Ways of Resolving Conflict, and one listing the Four Steps of Successful Win/Win Negotiation (listed below).

\section{WAYS OF RESOLVING CONFLICT}

Avoid conflict - Simply withdraw from any conflict

Smooth it over - Pretend there's no conflict and everything is OK.

Win at all Costs - Get what you want; the other person loses.

Compromise - Give up something you want to get something else that you want.

Win/win negotiation - Use creative problem solving to give both people what they want or need.

\section{FOUR STEPS FOR SUCCESSFUL WIN/WIN NEGOTIATION}

1. State your position. Use "I" statements, say what you want or need.

2. Listen to the other person's position. Find out what the other person needs or wants. Restate the other person's position to be sure that you understand.

3. Brainstorm win/win solutions. Take into account both partners' needs and wants. Be creative.

4. Agree on a solution. Try it out. If it does not work, start the process over again. 


\section{TAKING IT HOME RECAP}

Ask a few girls to share the strategies they developed for dealing with negative peer pressure, and their experiences trying out their strategies. Does having a strategy make it easier to deal with negative peer pressure?

\section{INSTRUCTIONS}

\section{STAR Model for Problem Solving (45 minutes)}

1. Ask each girl to think about a problem they have or had recently.

Example: A girl is walking down the street with her friend, and a man touches her in a way that makes her uncomfortable.

Ask the group:

- Which emotions do people feel when faced with a problem?

- Do these emotions ever warn us that we have a problem? In what ways?

These questions direct us to the first step for conflict solving:

Refer to the STAR model and explain the four steps to problem solving. (The STAR model stands for STOP, THINK, ACT, and REVIEW)
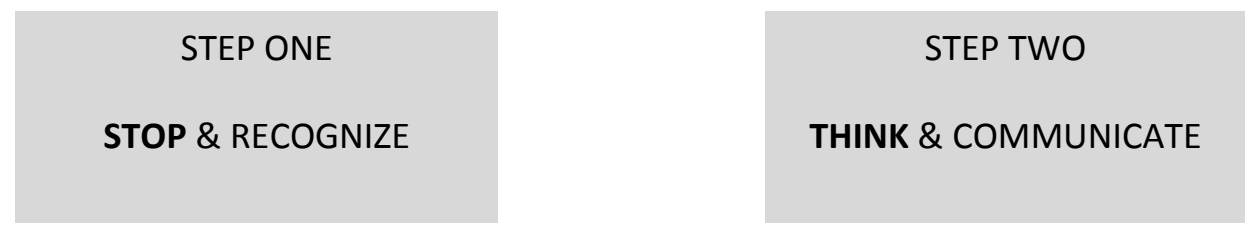

Inform the girls that thinking means separating fact and belief. Ask the girls to express their understanding of the concepts by asking:

- What is a fact?

- Example from above problem: The man touched the girl.

- What is a belief/opinion?

○ Example from above problem: Men are rude.

Clarify that to identify and think about a problem we need to see clearly between facts and beliefs/opinions.

\section{STEP THREE}

is the most obvious one:

TAKE ACTION
STEP FOUR

What do you do after action?

REFLECT \& REVIEW 
3. Hand out the "STAR problem-solving model" sheet as a way of reminding the girls of the four steps of problem solving.

4. In small groups choose two examples from the problem solving scenarios. Ask the groups to discuss the issues, and how to solve the problems using the STAR hand out. Have each group share their findings, using the discussion guidelines below.

5. Ask for volunteers from each group to act a role-play for one of the problems they chose to demonstrate how they would solve the problem. After each group does their role-play, let the entire group evaluate the role-play according to the following guidelines.

6. Facilitate a discussion using the following questions.

- What is the problem in the situation?

- What were the different solutions proposed to solve the problem?

- What were the consequences of these solutions?

- What solution was chosen?

- Do you think this is the best solution? Why or why not?

- What happens in life if problems do not get resolved?

\section{Resolving Conflict (45 minutes)}

1. Display a poster "Ways of Resolving Conflict" that you have pre-prepared.

2. Divide girls into 5 small groups and assign each group one of the above methods of conflict resolving. Provide the group with an example of a conflict situation. You can use the one below or come up with your own. Each group will role-play the situation using their assigned method of conflict resolution.

SAMPLE CONFLICT SITUATION: Maana wants go to her friend's house on Saturday night. But she has been doing badly in school and her parents refuse to let her go out with her friends until she improves her grades.

3. Have each group present their role plays. Then ask:

- Which methods usually cause problems?

- Which options are better strategies? Why? (The first three situations given above usually lead to problems and the latter two are more successful.)

- What are some other possible compromises or win-win solutions to this conflict?

(EXAMPLE: Maana says she is serious about improving her grades and suggests that she will get extra help from her teacher and study Friday night and all day Saturday if she can enjoy Saturday evening at the movies with her friends. Her parents agree to this compromise.)

4. Ask: What is the name of the process that leads to such a compromise agreement? (The answer that you are looking for is negotiation.) Ask girls to think of other examples where negotiation and compromise might bring an agreement.

5. Display and have girls read the poster "Four Steps of Successful Win/Win Negotiation" 
6. Ask for an example of how a win-win negotiation could work well. Read the example below. Ask the group to try and discover a way of resolving a conflict using a win/ win option. Ask volunteers to develop a role-play which show Kojo and Delasi working out a win-win solution to this problem.

Kojo and Delasi have been going out for a while and really like each other. Neither of them is seeing anyone else. Kojo however, still gets very jealous if Delasi pays attention to other guys. Recently, Delasi and her long-time friend Minkah started working together after school on an oral report they would have to make to their English class at school. Kojo feels like Minkah might be moving in on Delasi and he wants her to stop working with him. He says it's not right for them to meet after school and spend hours together. His friends have been making remarks about it. Besides, he wants to spend more time with her. Delasi likes Minkah, but only as a friend. She wants Kojo to trust her and to stop acting jealous all the time. She says there is no way she will stop working with Minkah; he's an " $A$ " student and she is hoping to bring up her grade by doing a really interesting report with him. How can Kojo and Delasi work out this situation so that each "wins'?

7. Facilitate a discussion using the following questions

- Why do people have so much trouble negotiating a solution to a conflict?

- How might people's feelings get in the way of a win/win solution?

- Could violence be an outcome in any of these situations? Which one? Why?

- What makes it easier to negotiate? What makes it harder?

- What are examples of situations in which you would be unwilling to compromise?

- Are there any current conflicts that you could resolve using negotiation?

- What solutions will you offer?

\section{TAKING IT HOME}

Suggest that the girls practice negotiation with a friend or family member next time a conflict arises.

To conclude the session, tell the girls to practice using the STAR model for solving a problem. It is best to start with a problem that is not very serious or important so they get practice problem solving with less emotionally charged situations. 
1. STOP \& RECOGNIZE

- Do I have a problem?

- What is my problem?

- How is my body affected?

- What feelings am I showing?

- What feelings am I keeping to myself?

2. THINK \& COMMUNICATE

- What do I want to happen?

- Who are the other people involved in the situation?

- What do they want to happen?

- What are the facts of the situation?

- What are my perceptions and values about the situation?

- Have I observed, gathered and remembered all the facts?

- Have I clearly expressed my feelings and thoughts?

- Have others clearly expressed their feelings and thoughts?

- What are some different solutions and their consequences?

- Are the consequences safe for and respectful to others?

- Have I consulted others affected about the range of solutions?

- What is the best solution?

3. ACT

- Choose the best situation

- Take action

- Choose to go back and 'stop \& recognize' again if there is no best solution

\section{REVIEW}

- Observe the consequences

- If there are no satisfying consequences go back to step 1 
With Friends:

1. Your friends want you to steal a car/ scooter/ bicycle with them and say you are weak if you won't join in.

2. Your mother/elder sister hates all of your friends and wants you to stop seeing them.

3. A friend borrowed a book or audio cassette but does not return it. You want it back.

4. You and your friends have been playing soccer in a nearby park/open ground all year and now a gang of older boys are using it at the same time.

5. Another girl is bothering your boyfriend.

$\underline{\text { In School: }}$

1. You hand in some homework to your teacher at the same time as all the other students. The next week she hands them back and asks you why you didn't hand any in.

2. A teacher continually says that you are causing trouble in class. You consider that you are being unfairly treated. 


\section{Session 15: Setting Goals}

\section{Session Objectives:}

By the end of this session, girls will be able to:

- Explain the purpose of goal setting

- Describe the process of setting and achieving goals

- Set clear goals

\section{Materials Needed:}

- Strips of paper with short and long term goals, enough for each girl

- Container for strips of paper with goals

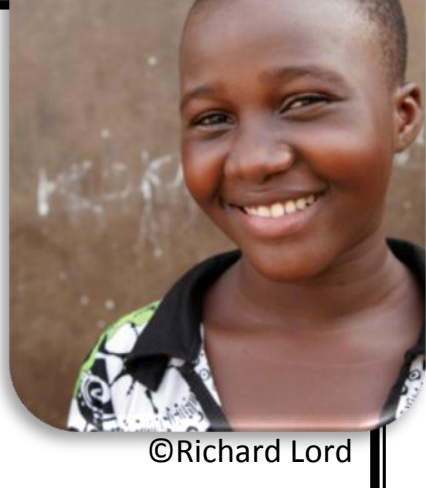

- Flipchart and markers

- Paper and pens or pencils for each girl

\section{Session Outline:}

- Short and Long Term Goals (30 minutes)

- Making SMART Goals (60 minutes)

Total Time: 90 minutes

BEFORE THE SESSION: Prepare strips of paper with short and long term goals (p. 74). Make sure you at least one for each girl.

\section{TAKING IT HOME RECAP}

Ask how many of the girls practiced negotiation with a friend or family member during a conflict. Have a few volunteers share about the experience. Did negotiating help solve the conflict?

Ask a few girls to share their experience using the STAR model for solving a problem. Was the model useful?

\section{BACKGROUND NOTES}

A goal is an achievement and accomplishment towards which our efforts are directed. It can be something to do, someplace to go, or something to have. Goals give us something to look forward to and can give us motivation and energy. To set a goal, we must gather information and make decisions and choices. We must learn about what we want to achieve. Goals should be specific, practical, and have a deadline. Goals should be reasonable and manageable. Something realistic and easy to manage 
makes achieving it easier and creates confidence to move to other, greater goals. Thinking about the expected benefits can be motivating. To help achieve a goal, it is helpful to have a plan with steps that are needed to achieve the goal, and also think about possible difficulties and how they can be overcome.

\section{INSTRUCTIONS}

\section{Short and Long Term Goals (30 minutes)}

1. Draw a rough sketch of a soccer field on a sheet of flipchart paper. Ask:

- What is the purpose of a soccer match? (To win)

- How do you do that? (Score goals)

- How does a team score goals or runs? (It has a plan, it practises, and it plays as a team)

2. Discuss that life is like this. We must have a purpose - these are our goals.

- What are examples of goals?

- Why do people set goals?

3. Ask each girl to come up one at a time, pull a strip of paper from the container and read the goal on the paper. Without telling them why, direct each girl to one side of the room or the other, depending on your determination of whether the goal is short-term or long-term. When everyone has stated a goal, ask a volunteer to answer the following questions:

- Why are you standing in two different groups?

- What is the difference between the two groups?

4. When someone answers that one group named goals that can be achieved quickly (short-term goals) and the other group named goals that take longer to achieve (longer-term goals), ask everyone to take their seats.

\section{Making SMART Goals (60 minutes)}

1. Ask for suggestions about "what makes a good goal". After several ideas have been shared, explain that we are more likely to achieve a goal if it is SMART; write the following acronym on the flip chart.

S- Specific

M- Measurable

A- Achievable

R- Realistic

T- Time-bound

Reinforce the fact that because a goal should be realistic and achievable it might mean setting a series of small goals that help us make progress towards achieving a larger goal.

2. Give the following examples of "SMART" goals. Ask the girls to identify their own "SMART" short-term goal, achievable by next week and why they want to achieve this goal. 
Some examples:

"I will do well on my math test on Thursday"

"I will sweep my house and prepare dinner for my family once this week"

"I will help my mother sell fish in the market after school three days this week"

"I will exercise for an hour every Saturday in the morning from tomorrow"

"I will weed and clear the empty land in the neighbourhood to plant maize by next month"

3. Have the girls meet in pairs to share their goal with one another. Give each girl a piece of paper andask them to draw a picture or write a statement of her goal. When all are finished each girl can show her picture and state her goal.

4. Facilitate a discussion using the following questions.

- Have you ever set a goal before?

- Is this goal different? If so, how? Is the goal SMART?

- How is it beneficial to set goals?

- What are some of the difficulties of making goals?

Inform the group that next week we will check to see who managed to achieve her goal, and then look at longer term goals.

\section{TAKING IT HOME}

Ask the girls to take action to achieve their short-term goal and talk about it at next week's session. Instruct them to write in their program journal about 2-4 steps they'll take to achieve their goal.

\section{PLANNING AHEAD: SESSION 20}

Review with the girls that they will be doing a presentation or performing a skit for their parents and other adults in the last session. Answer any questions regarding the expectations for this assignment. Encourage the girls to be creative about the way they present their topic.

Match the girls into pairs based on the topics that they are interested in presenting. Try to ensure that no two groups cover the same topic, and that a broad range of topics are covered. They MAY choose to present on a topic that has not yet been covered. 


\begin{tabular}{|c|}
\hline Finish my homework tonight \\
\hline Help my mother sell fish at the market after school tomorrow \\
\hline Do well on my Math test next Monday \\
\hline Become a teacher \\
\hline Complete Senior High School \\
\hline Go to university \\
\hline Clean my room this week \\
\hline Organize my books \\
\hline Open my own business \\
\hline Buy a new pair of jeans \\
\hline Save enough money to take a computer course \\
\hline Save some small amount of money every week \\
\hline Become more assertive \\
\hline Read a story book every month \\
\hline Become a nurse \\
\hline Build a house \\
\hline Get married \\
\hline Pass my Junior High School exams \\
\hline Have children \\
\hline Get a good job \\
\hline
\end{tabular}

(Facilitators can add their own examples to have enough goals for each girl.) 
Session 16: Making Plans

Session Objectives:

By the end of this session, girls will be able to:

- Describe and use a simple planning process for achieving goals

- Explore the importance of creating and achieving personal goals

\section{Materials Needed:}

- One medium-sized ball per group (8-10 girls per group)

- Flip chart, easel, markers

- SMART goals written on flip chart (from previous session)

- "Setting my goals" worksheet for each girl (p. 78)

\section{Session Outline:}

- Hopes and Dreams (20 minutes)

- The "Five Friends" (70 minutes)

\section{TAKING IT HOME RECAP}

Ask the girls to report on the short-term goals that they had set for themselves the previous week. Did they achieve their goals? Why did some achieve their goals and others not? (Explain that you need a plan to go with your goals. It is important to have SMART goals but it is equally important to have detailed, clear plans of action.)

\section{RIGHT Hopes and Dreams (20 minutes)}

1. Begin with a discussion using the following questions:

- What is a hope? What is a dream?

- What is one thing you hope for in the next year?

2. Divide the girls into groups of 8-10.

3. Ask each group to form a circle. 
4. Explain and demonstrate that:

- In this game you will talk about your hopes and dreams. Ask girls to think of one thing they hope for in their future. Once they have a hope in mind, ask them to use their magic pen (their finger) to write or draw their hope in the air. They should complete this task quietly.

- Explain that in this game, the ball represents their hope. The girls' task is to keep the ball, their hope, in the air.

- Ask for a volunteer from each group to start the game.

- The starting girl will toss the ball high into the centre of the circle. Another member of the group will try to hit the ball to someone other than the person from whom the ball was received.

- Before hitting the ball, the girls must call out their own name. This will tell other group members that someone has claimed the ball.

- As the ball is hit around the circle, the entire group will count out loud the number of hits.

- If the ball goes out of the circle it stays in play if the group keeps it in the air and hits it back into the circle.

- Each time the ball touches the ground, the counting of hits must begin again.

5. Encourage the group to improve the number of hits during each new round of play.

6. The game ends at your discretion.

Watch for:

- Is each girl hitting the ball?

- Are the girls counting the number of hits out loud?

7. Facilitate a discussion using the following questions:

- How did it feel to help your team keep the ball in the air?

- How did you feel when the ball touched the ground?

- When are some times in real life that encouragement from others has helped you complete a task?

- Imagine that the ball represents hope. How can we encourage each other to stay hopeful?

\section{The "Five Friends" (70 minutes)}

1. Review SMART goals on flip chart. Now tell the group that we will explore how to set clear plans. 
2. Introduce the "five friends" of a good plan. Hold up your hand and for each finger; list one of the friends:

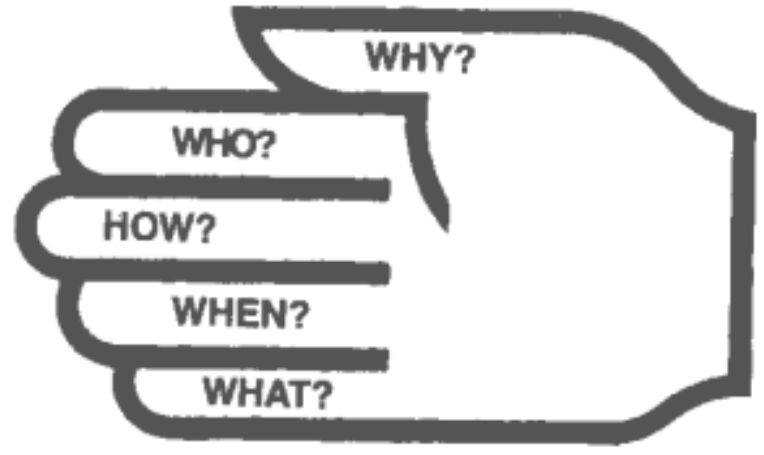

WHY? The reasons for working towards a goal WHO? The person who will carry out the plan HOW? The step-by-step actions required WHEN? The time within which each step will be done and the goal achieved WHAT? The resources needed to achieve the goal

3. Play a memory game to learn the "five friends". Ask all the girls to stand and raise one hand in front of them. Go around the circle and have each girl name the "five friends" on his fingers. Those who name them correctly can sit down. Others try again until everyone has listed the "five friends" correctly.

4. Explain that each girl will make an individual plan of action using the "five friends". First brainstorm what parts of our life we need to develop goals and plans for. After the brainstorm give each girl a setting my goals worksheet and add any parts of life that the group wanted added to the list in the blank rows. Then ask the girls to target five areas of life that they will develop the plans for. They have 15-20 minutes to work alone.

5. Ask the girls to present their plans to one another in small groups. As they are presented, ask the girls to give feedback and suggestions to each other.

6. Reassemble the full group and facilitate a discussion using the following questions:

- What difficulties did you have making your plans?

- Do you have any questions about the "five friends" and how to make a plan?

- How will the "five friends" help you achieve your goals?

- How can the "five friends" be useful in your life?

- Are having goals important in life? Why or why not?

\section{TAKING IT HOME}

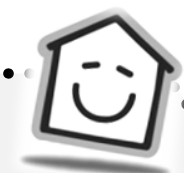

Discuss the idea that it is always easier to achieve goals when you have the support and encouragement from a friend, family member, or teacher. Ask the girls to begin working toward one or more of their goals and discussing their plans and progress with someone close to them who can provide this support and encouragement. 


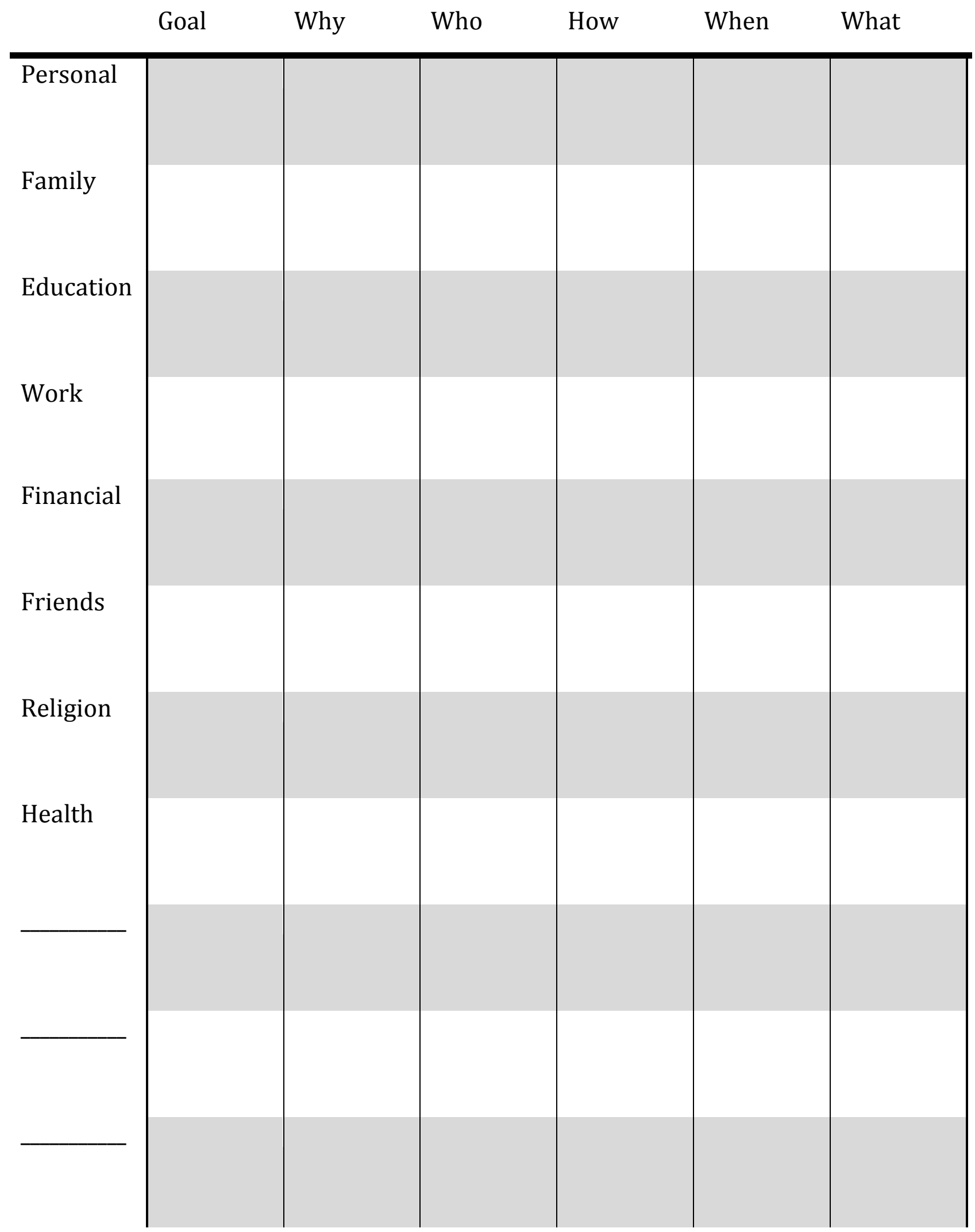


Session Objectives:

By the end of this session, girls will be able to:

- Identify women leaders or leadership groups in the community

- Understand different ways in which women can participate in politics and decision-making of the community

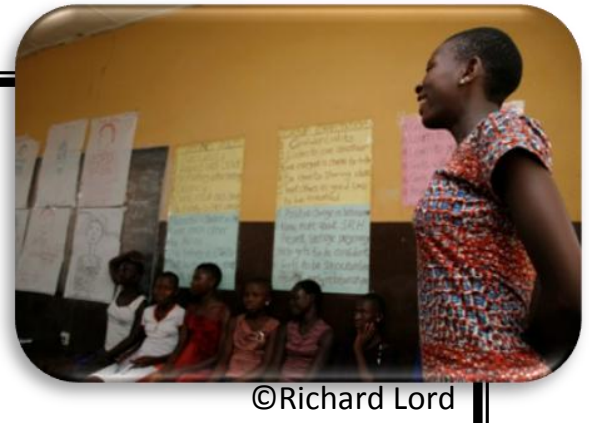

\section{Materials Needed:}

- $\quad$ Flip chart, easel, markers

- "Women's Leadership in the Community" Handout for each small group (p. 83)

\section{Session Outline:}

- Secret Leader (20 minutes)

- Qualities of Leaders (30 minutes)

- Women as Leaders (40 minutes)

Total Time: 90 minutes

\section{TAKING IT HOME RECAP}

Ask for a few volunteers to share about the progress they are making towards their goal. Who have they discussed their goals with? How has sharing their plans with someone close to them helped in making progress towards their goals?

\section{INSTRUCTIONS}

\section{RIGHT Secret Leader (20 minutes)}

1. Begin with a discussion using the following questions:

- What are some qualities or characteristics of a person who is a leader?

- What are some qualities or characteristics of a person who is a follower?

2. Ask the girls to form a large circle.

3. Ask for one volunteer to be the Guesser. Ask the Guesser to leave the play area temporarily.

4. Explain that the Guesser will return to the centre of the circle, and will have three guesses to identify the Secret Leader.

5. Once the Guesser has left the play area, quietly select one volunteer to be the Secret Leader. 
6. Explain and demonstrate that:

- The Secret Leader will perform a series of different actions, such as hand clapping, foot stomping, head nodding, etc. Encourage the Secret Leader to use imagination in performing different actions.

- The Secret Leader will change the action whenever it is safe to do so (without being seen).

- Each member of the circle must follow the Secret Leader's actions by looking at the girl directly across the circle. The girls should not look directly at the Secret Leader.

- The Guesser will return to the centre of the circle while an action is underway.

- The Guesser has three chances to point to the person he or she thinks is the Secret Leader.

- If the Guesser identifies the Secret Leader, the Guesser may select a volunteer to be the Guesser for the next round.

- If the Guesser does not identify the Secret Leader after 3 guesses, the Secret Leader must step forward. She can choose to be the next Guesser or select a volunteer for the role.

- The group's actions should continue while the Guesser is trying to identify the Secret Leader.

7. The game ends at your discretion.

Watch for:

- Is the Secret Leader performing simple actions that can be followed easily?

- Is each player looking directly across the circle at the player opposite?

8. Facilitate a conversation using the following questions:

- Are real leaders always visible?

- Is it possible to lead without being noticed by everybody?

- What are some ways you can lead in your family, school, or community?

- What does it mean to "lead by example"?

\section{Qualities of Leaders (30 minutes)}

1. Ask the group to make a list of official leaders in their community and note the difference in number of men to number of women.

2. Explain that in most of our communities the official leaders are men. This session wishes to explore how women can be leaders in the communities and participate in politics and decision making.

3. On a flip chart write the words "Women Leaders". Ask the girls to list down the names of women leaders they are aware of. Ask them to list down the qualities that make them leaders. Now write the words "Male Leaders" and ask them to name qualities of good male leaders. Write these down.

4. Ask the group whether the qualities of women leaders are different from women in the community. What are those? 
5. Cross out "Women Leaders" and replace it with "Male Leaders". Cross out "Male Leaders" and write "Women Leaders". Ask what they think of the lists now.

- Does the first list of qualities apply to men as well as women? Why or why not?

- Does the second list apply to women as well as men? Why or why not?

- Is it necessary to be a great speaker or public motivator to be a leader? Do you know of any "quiet" leaders in your community?

- What prevents women from being leaders?

Note: These questions will spark lively discussion about gender-specific attributes. Relate the discussion to the process of gender stereotyping. Emphasise the learned nature of gender roles.

\section{Women as Leaders (40 minutes)}

1. Read the story, "Women's Leadership in the Community"

2. Ask the girls to divide into small groups and discuss:

- What did Ata do in the story?

- What were some of her leadership characteristics?

- How do these characteristics compare with men's leadership characteristics?

- Why was Ata an effective leader?

- What is the difference between this kind of leadership and the leadership of elected leaders or traditional elders?

3. After the small groups have met for about 10 minutes, bring the full group together. Ask a member of each small group to share some ideas from the discussion.

4. Ask the girls to think about their own communities:

- Who are some good women leaders or leadership groups?

- Why did you choose these women or groups?

- How can these leaders be a source of support in areas of concern to young people?

\section{TAKING IT HOME}

Ask the girls to talk to one woman leader in their community and ask her about her experiences as a leader. Below are ideas of some questions.

- What does she find exciting and rewarding about being a leader?

- What has been challenging or difficult for her?

- What qualities does she have that she thinks has helped her in her position?

- What does she think young women can do to increase the political and decision-making power of women in general? 
2

PLANNING AHEAD: SESSION 20

Check in with the girls regarding their presentations.

Find out if they are making progress and answer any questions. Provide assistance and briefly review any topics as needed. 
Ata lives in a village with her husband Ebo and their three children, two boys and a girl. All three were attending the village school, but Ebo did not want his daughter Adzo to study further. So, Adzo dropped out of school.

Ata was very upset and tried to convince Ebo to send Adzo back to school. Ebo would not hear of this. He believed that educating a girl was a waste of time and money. Besides, it might spoil her.

Ata was very disappointed. She wanted her daughter to be educated. Now that Ata was attending the newly formed education centre in the village, she understood the importance of educating a girl. She talked to the other women in her community. After meeting several times, they all decided that their daughters must go to school. They included the village leader and schoolteacher in their discussions. The women's group then went to each household and convinced the men that the girls must go to school. The men had to agree. They started sending their girls to school. 


\section{Session 18: Teamwork}

Session Objectives:

By the end of this session, girls will be able to:

- Develop a contract with someone else within the group in order to achieve personal goals

- Describe the qualities of effective team support

\section{Materials Needed:}

- $\quad$ Flip chart, easel, markers

- Photo of Ghana soccer team (p. 87)

- A "My Contract" handout for each girl (p. 88)

\section{Session Outline:}

- Human Knot (30 minutes)

- Being a Team Player (40 minutes)

- Taking it Home: My Contract (20 minutes)

Total Time: 90 minutes

\section{TAKING IT HOME RECAP:}

Ask the girls to share about their conversations with a woman leader in their community. Who did they talk to? How did the women leaders answer the questions the girls asked?

\section{RIGHT Human Knot (30 minutes)}

1. Divide the girls into groups of 8-10.

2. Ask each group to form a circle facing inward.

3. Explain and demonstrate that:

- Each player will reach into the centre of the circle and firmly clasp hands or wrists with two different people.

- Without letting go, players must now work together and try to untangle themselves and form a circle.

4. The game finishes when each group's human knot is untangled.

5. Encourage groups that finish quickly to offer support to other groups that are still tangled. 
Watch for:

- Are all players actively involved in problem solving how to untangle the human knot?

- Are the players in each group working together?

6. Facilitate a discussion using the following questions:

- What were some things your team did together to untangle the knot?

- What did you do to support other teams?

- What do you think would happen if you had to untangle the knot alone?

- What are some examples of times in your daily life when it is important to work together?

- Why is it important to work together to achieve a goal?

\section{Being a Team Player (40 minutes)}

1. Review the SMART goals and the "five friends" planning method. Inform the group that we want to focus this session on the WHAT part of the "five friends". WHAT is about the resources we need to achieve the goals that we set for ourselves.

2. Ask the group to brainstorm what are the resources needed to often achieve our goals. The group will come up with resources such as money, family, advice offices (e.g. career guidance), books and information, friends, networks. You can add any of these.

3. Inform the group that often we think of money as the primary resource in life but that in fact people are. Money is secondary to people. Our primary resources are our friends. The focus of this last session is how we as people can be resources to one another.

4. Display the photo of the Ghana soccer team. Remind the girls of the discussion around goals - how we need to set goals in our life, just like a soccer team needs goals to win a game. Ask:

- How does a team score goals or runs? (It has a plan, it practises, and it plays as a team)

- In what way does it hinder a team if it does not play as a team but simply a group of individuals?

- In what way does it help a team if it plays as a team rather than as simply a group of individuals?

- In what way is this similar to life?

- What are the qualities of a good football or cricket team?

- Are these the same as qualities for any kind of teamwork? If not, what can we add or subtract?

5. Inform the group that we will now develop small role-plays:

Each girl is to choose one of the five goals that she developed on the work sheet in the last session. Each girl then shares this with others in a small group. Then from all the goals shared choose one or a combination of some that are similar to develop a 3-5 minutes role-play. Groups will have 15 minutes to develop the role-play.

The role-play must demonstrate the following: (write on a flipchart)

- What the goal is 
- Any challenges, difficulties, or opposition that exists in being able to attain the goal

- How friends acting as a team can help the person overcome the opposition and achieve their goal.

6. After all the groups have acted their role-play discuss:

- What was each goal?

- What were the challenges or opposition?

- How did the team help the person overcome the opposition and achieve their goal?

- What were the qualities of the teams?

- In what ways does team-work empower us to achieve our goals and plan

\section{TAKING IT HOME (20 minutes)}

Ask the group to form pairs and inform them that they are going to enter into a contract will that person to achieve another short-term or medium-term goal. The contract is a mechanism of encouraging teamwork and helping individuals achieve their goals.

Give each girl one of the handouts "MY CONTRACT." Give them 20 minutes to fill out the contract (their own and their friend's)

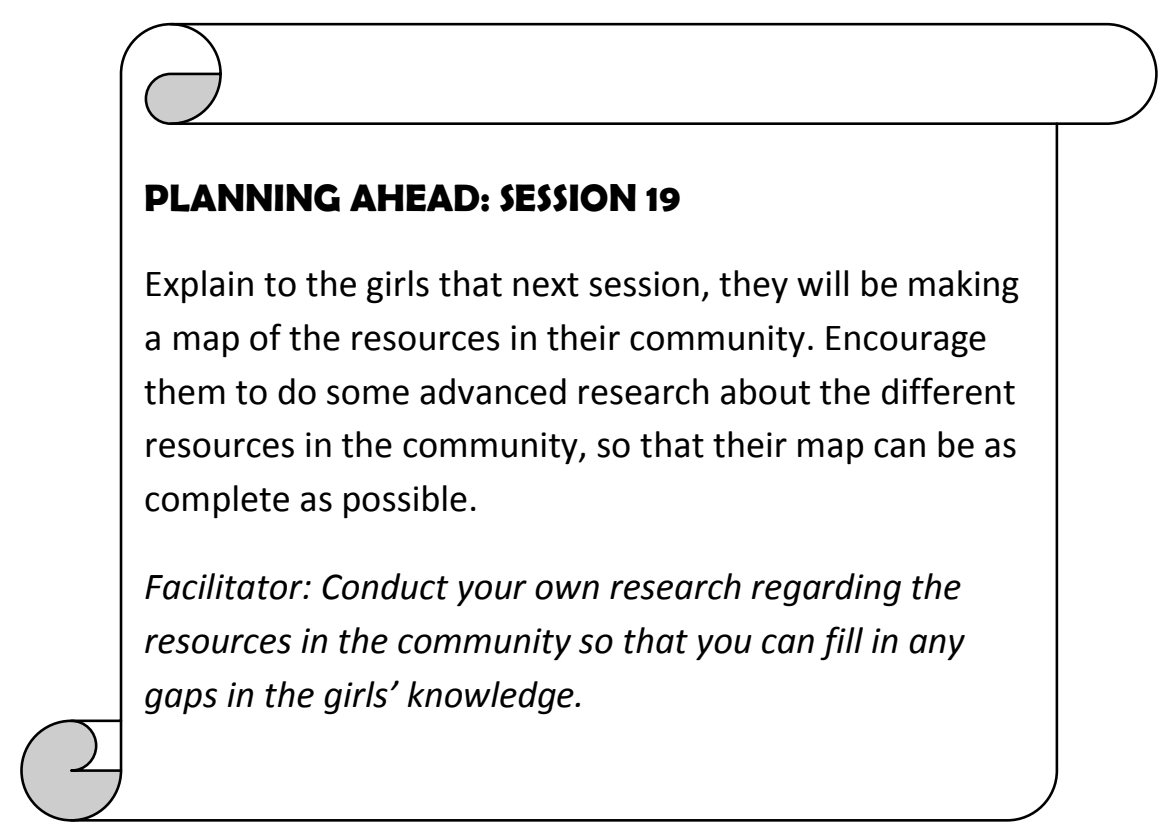




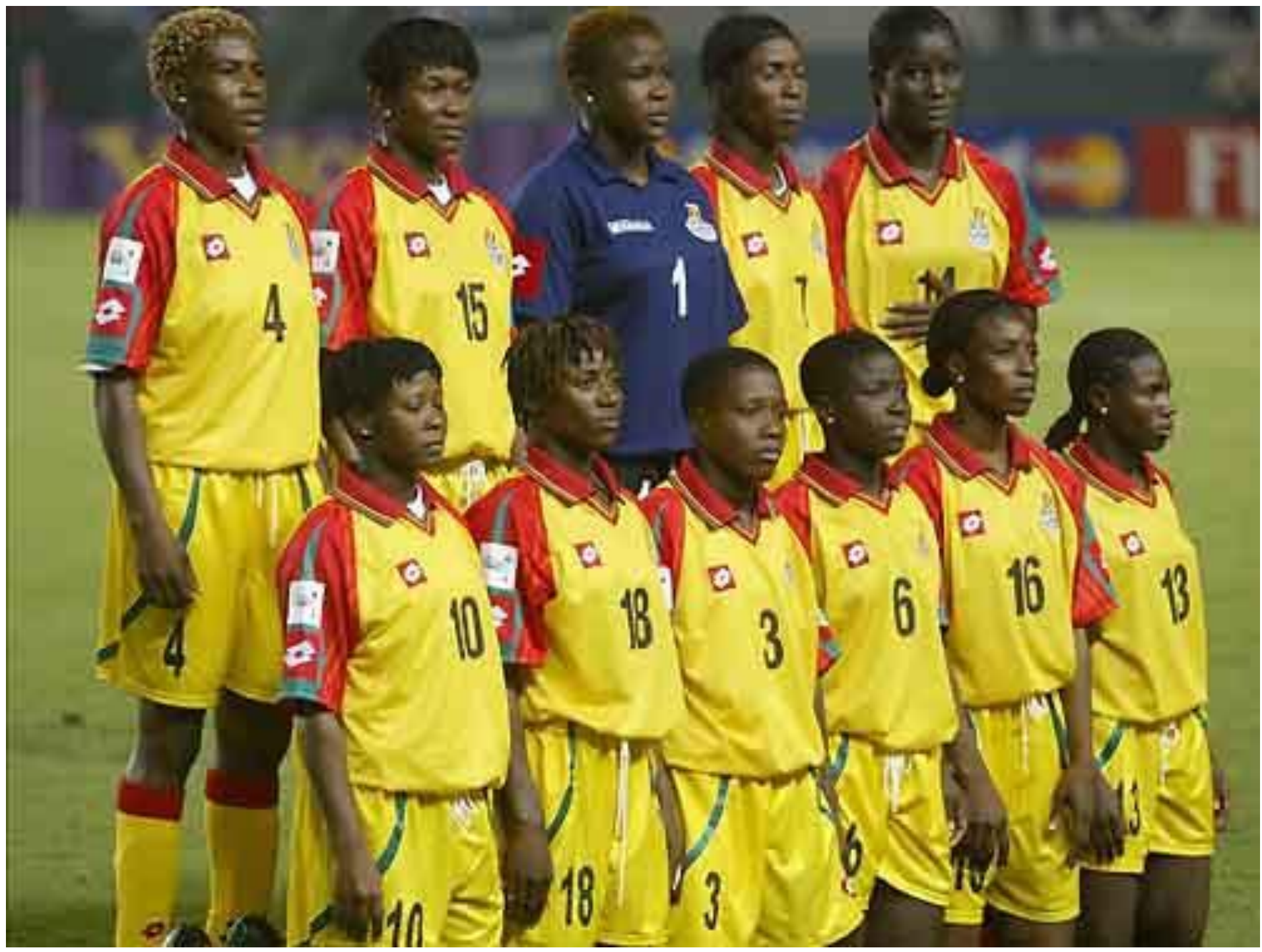


MY CONTRACT

\section{PART A}

$\mathrm{I}$, do hereby declare that I will achieve the following

(Name)

short-term goal on or before: My goal is to

(Date)

In order to achieve my goal, I will complete the following steps:

1.

2.

3.

4.

PART B

I, do hereby declare that I will support

(Partner's Name)

in accomplishing her goal by

(Date)

I agree to do the following three things to support my partner's work toward her/his goal:

1.

2.

3.

Upon completion of the goal, I will reward her by

We have confidence and faith in each other and strongly believe that we will achieve our goals in the stated time.

Signed:

(Name)

Signed:

(Partner's Name)

Date: 
Session Objectives:

By the end of this session, girls will be able to:

- Define what a community is

- Identify different resources within the community which can assist people in many ways

- Create a community map of resources that can be used in daily lives

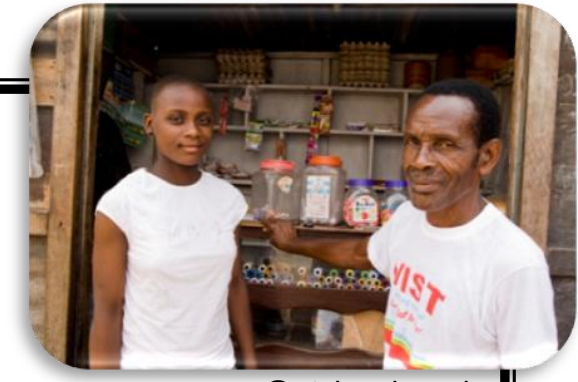

(C)Richard Lord

- Think about ways to use community resources to help solve problems

- Identify some ideas for action in the community

- Be aware of and able to describe responsibilities within the community

\section{Materials Needed:}

- Paper and pens or pencils for small groups

- A large piece of cardboard (or newsprint) and markers

- Problem cards for Using Community Resources (p. 93)

- Flip chart, easel, markers

- Newsprint and markers for small groups

\section{Session Outline:}

- Mapping Community Resources (45 minutes)

- Using Community Resources (20 minutes)

- My Role in the Community (20 minutes)

Time: 90 minutes

\section{TAKING IT HOME RECAP:}

Have the girls meet with their partners and discuss their progress towards achieving the goal in their contract. Allow about 5 minutes to talk with their partners, then bring the group back together. Are they on track with the steps they wrote down? Are they doing their part to help their

\section{INSTRUCTIONS}

\section{Mapping Community Resources (45 minutes)}

1. Tell the girls that we are trying to explore their community.

2. Brainstorm with the girls and ask them to define the term 'community.' The likely answers are a group of people living in the same geographical area, people doing the same kind of work, people speaking the same language, people coming from the same native area, etc. 
3. List the answers on a flip chart and coin a definition for "community".

4. Divide the girls into groups of 3-5. Ask each group to write down as many resources in their community as they can think of. Ask them to think about different categories of resources, including education, health, water, sanitation, electricity, fuel, legal aid, and financial institutions.

5. Bring everyone back together and ask each group to share their list. As each group talks, write down all of the resources mentioned on a flip chart to create one master list.

6. In a large group show the girls a large piece of cardboard (or newsprint) and explain that they will create a community resource map that will show where all of the resources they listed are located. They can also add new places that they didn't think of before.

7. Ask the girls to draw a general map of the community on the piece of cardboard. Ask them to draw the community boundaries, major roads, rivers, major places, etc. by using different symbols. Let the girls organise themselves.

8. Ask the girls to draw symbols on the map for all the resources they listed. A good way to do this is to give each team a turn to put one resource on the map and rotate until everything is on the map. Encourage the girls to be creative with the symbols.

9. Have the girls look at the completed map and ask:

- Which are the most used resources, by who and why?

- Do you have access to those resources? If Yes, how? If not, why not?

- What can be done to have more access?

- What needs exist in the community for which resources are currently not available?

- In what ways might available resources be used to meet these needs?

- What can be done to fill in resource gaps in the community?

\section{Using Community Resources (20 minutes)}

1. Tell the girls that they will now have a chance to think about how to use these resources to solve problems they or their families might encounter. Divide them into groups with four or fewer members. Give each group one problem card from the samples provided or create your own problem cards. Have them read the cards or read the cards to them. Ask them to think about the problem. Then say:

- Identify the resource or resources on the map you will use to solve the problem and how you will use the resource.

- Identify other problems in your community and how you will use the available resources to solve these problems.

2. Have the groups take turns presenting their ideas. Encourage everyone to add her ideas. Continue until all the problems have been discussed. 


\section{My Role in the Community (20 minutes)}

1. Divide the girls into small groups of four or five. Tell them to imagine they are special assistants to the elders. They have the power to make any changes they want in their community. In small groups brainstorm what changes they would like to make, list them on newsprint and report back to large group.

2. Ask the group to identify the changes that are realistic - those that could be made it both young people and adults put effort into them. Circle the realistic changes or give examples. Point out that some changes are unrealistic in the immediate future - they cannot be made now no matter how much someone wants the changes or how much someone tries.

3. Give each small group a piece of newsprint and a marker. Have them choose one realistic problem they want to work on from the list of changes. Instruct the girls to make strategies about making changes to eliminate the problem If they are feeling stuck help them by saying they could do...

- Something mentally, such as coming up with a new approach or idea

- Something physically, such a cleaning, repairing or building

- Something financially, such as saving a small amount of money each week to contribute to a new community centre

- Something socially to help people, such as visit the sick or elderly

- Something politically to change rules or laws, such as writing letters to the district chief executive, social and political leaders.

4. Encourage the girls to be creative and to write their strategies on newsprint. If necessary, choose one of the problems from their list and give strategies for change as an example.

5. Allow 5-10 minutes, then have each group report their strategies

6. Facilitate a discussion using the following questions

- Has someone tried to solve these problems before? If so, what was the result?

- Can you think of any community problems that have been resolved by young men such as you? Give examples.

- How much time would you commit to solving one of these problems?

- What community development project have you been involved in?

- What can you gain from participating in community development? (Some ideas could be: something interesting to do during leisure hours, new relationships with people who are interesting or helpful, a feeling of accomplishment, learning new skills.) 


\section{TAKING IT HOME}

Ask the girls to speak with family and friends about community resources. Ask them which ones they have used. Share other resources they may not know about with them.

Ask the girls to, with a group of friends or classmates, select a community change project they would like to work on and decide on a strategy for addressing the change and act on it.

They may also conduct a field trip to a community service project and spend some time volunteering there.

PLANNING AHEAD: SESSION 20

Check in with the girls regarding their presentations for the next session. Answer any questions and provide assistance as needed. 


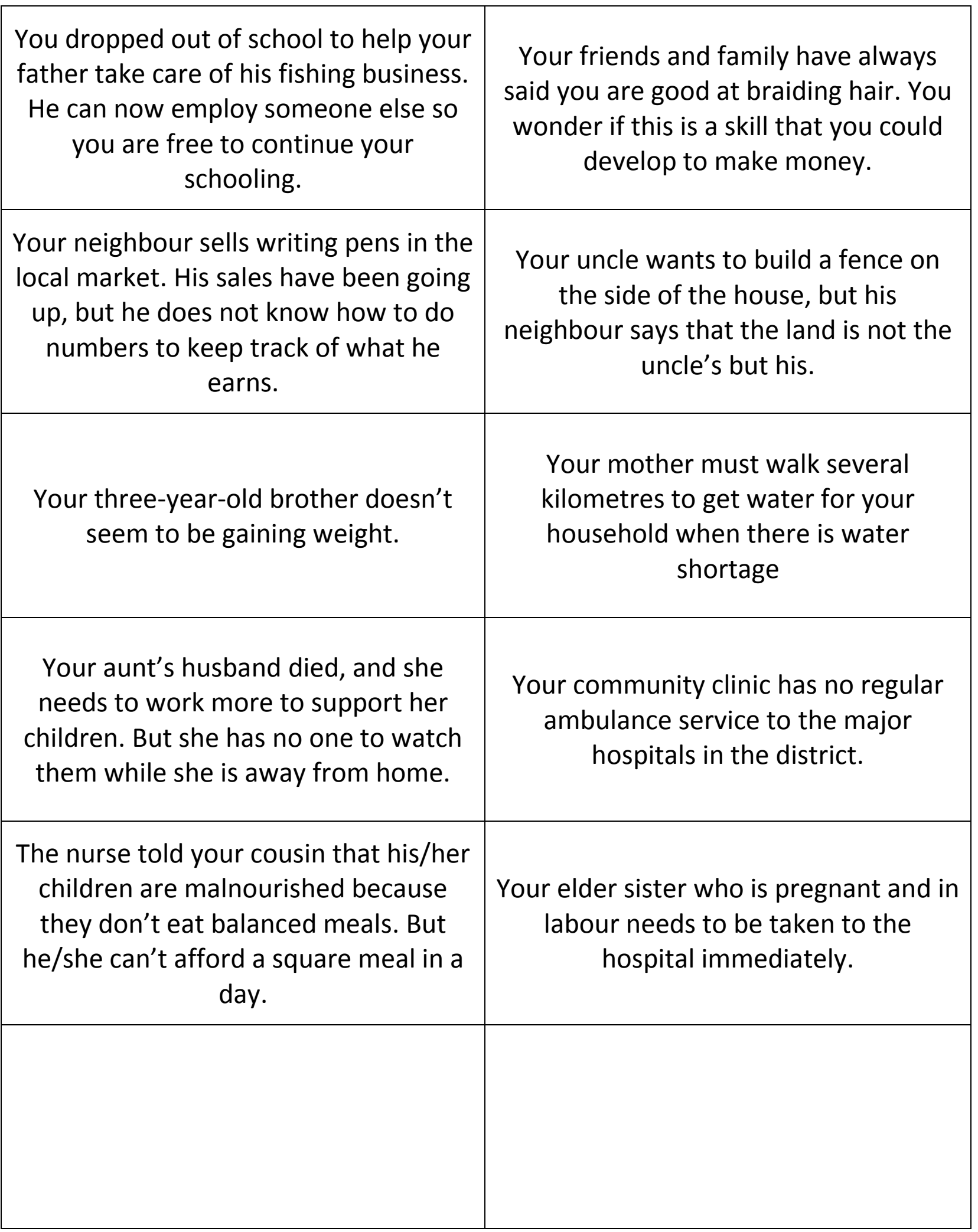




\section{Session 20: Bringing It All Together}

Session Objectives:

By the end of this session, girls will be able to:

- Review and reflect on what they have learned throughout this course

- Demonstrate knowledge of a particular topic in front of a group

- Further develop their self-expression and communication skills

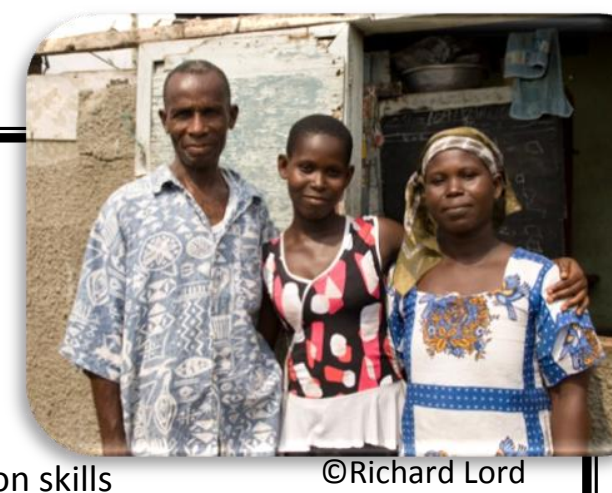

\section{Materials Needed:}

- None

\section{Session Outline:}

- Presentations (60-90 minutes)

\section{TAKING IT HOME RECAP}

Ask a few girls to share what they learned through their conversations about community resources. Were they able to teach any of their family or friends about a resource they weren't aware of?

Ask a few girls to share what their community change project is and what progress they have made. What challenges have they encountered? Have the group make suggestions for how to overcome the challenges.

\section{INSTRUCTIONS}

1. Welcome the parents and adults to the session, and ask them to introduce themselves to the group.

2. Have each pair of girls present their topic in front of the group. Try to keep the presentations to a maximum of 5-7 minutes and allow the adults to ask the girls questions after each presentation.

3. After all of the groups have presented, go around the room and ask each girl to answer this question:

What is the one thing you have learned during the Life Skills module that you think will be most useful for you in your life? 